\title{
A Systematic Review of Directly Applied Biologic Therapies for Acute Spinal Cord Injury
}

\author{
Brian K. Kwon, ${ }^{1,2}$ Elena B. Okon, ${ }^{2}$ Ward Plunet, ${ }^{2}$ Darryl Baptiste, ${ }^{3}$ Karim Fouad, ${ }^{4}$ Jessica Hillyer, \\ Lynne C. Weaver, ${ }^{5}$ Michael G. Fehlings, ${ }^{3}$ and Wolfram Tetzlaff ${ }^{2}$
}

\begin{abstract}
An increasing number of therapies for spinal cord injury (SCI) are emerging from the laboratory and seeking translation into human clinical trials. Many of these are administered as soon as possible after injury with the hope of attenuating secondary damage and maximizing the extent of spared neurologic tissue. In this article, we systematically reviewed the available preclinical research on such neuroprotective therapies that are administered in a non-invasive manner for acute SCI. Specifically, we reviewed treatments that have a relatively high potential for translation due to the fact that they are already used in human clinical applications or are available in a form that could be administered to humans. These included: erythropoietin, NSAIDs, anti-CD11d antibodies, minocycline, progesterone, estrogen, magnesium, riluzole, polyethylene glycol, atorvastatin, inosine, and pioglitazone. The literature was systematically reviewed to examine studies in which an in vivo animal model was utilized to assess the efficacy of the therapy in a traumatic spinal cord injury paradigm. Using these criteria, 122 studies were identified and reviewed in detail. Wide variations exist in the animal species, injury models, and experimental designs reported in the preclinical literature on the therapies reviewed. The review highlights the extent of investigation that has occurred in these specific therapies, and points out gaps in our knowledge that would be potentially valuable prior to human translation.
\end{abstract}

Key words: anti-nogo antibodies; biologic therapies; cethrin; chondroitinase ABC; spinal cord injury

\section{Introduction}

A NUMBER OF BIOLOGICAL THERAPEUTIC INTERVENTIONS have been developed for traumatic spinal cord injury (SCI) in which the treatment reaches the injured spinal cord by direct application rather than by systemic distribution. While their mechanisms of action may share similarities with some pharmacologic agents drugs (reviewed in a separate article), their mode of direct application imposes practical considerations that are distinct from drugs, which can be administered orally or parenterally. The delivery of biological therapeutic interventions to the spinal cord can be achieved by any of three possible routes, namely:

1. Applying the agent to the overlying dura (and depending on penetration through the dura, diffusion through the cerebrospinal fluid [CSF] within the intrathecal space and into the cord)
2. Injecting the agent into the intrathecal space (and depending on its diffusion through the CSF into the cord)

3. Injecting the agent directly into the spinal cord

Within the enormous scope of pre-clinical investigation for SCI, there are numerous compounds that have been evaluated after some form of direct application to the spinal cord. Here, we limit the scope of this systematic review to three therapeutic strategies that have received considerable attention in the past two decades and are in various stages of clinical translation to promote endogenous neuroregenerative repair following SCI: (1) the degradation of inhibitory chondroitin sulfate proteoglycans with chondroitinase ABC; (2) the neutralization of myelin-mediated inhibition of neurite outgrowth with anti-Nogo (IN-1) antibodies or other Nogorelated approaches; and (3) the inhibition of Rho activation. The present systematic review provides an overview of the body of pre-clinical evidence that supports, or fails to support,

\footnotetext{
${ }^{1}$ Combined Neurosurgical and Orthopaedic Spine Program (CNOSP), Department of Orthopaedics, ${ }^{2}$ International Collaboration on Repair Discoveries (ICORD), University of British Columbia, Vancouver, British Columbia, Canada.

${ }^{3}$ Toronto Western Hospital, University of Toronto, Toronto, Ontario, Canada.

${ }^{4}$ Faculty of Rehabilitation Medicine, University of Alberta, Edmonton, Alberta, Canada.

${ }^{5}$ Robarts Research Institute, University of Western Ontario, London, Ontario, Canada.
} 
the translation of the aforementioned neuroregenerative biological therapeutic strategies into human trials for SCI.

\section{Methods}

A PubMed search was conducted on "the therapy" and "spinal cord injury" (e.g., "chondroitinase ABC and spinal cord injury"). From the list of studies generated through this fairly indiscriminate search, we then applied the following inclusion criteria to systematically review the pre-clinical literature on biological therapies applicable to SCI:

1. Studies that include testing of the therapy in an in vivo animal model of spinal cord injury (i.e., exclusively in vitro studies were excluded)

2. Studies in which the spinal cord is traumatically injured with a contusion or compression device or is partially or completely transected (i.e., non-traumatic local or global ischemia, photochemical reaction, traumatic root avulsion, or dorsal root entry zone models were excluded)

3. At least two peer-reviewed publications available on the therapy (i.e., biological therapies supported by less than two peer-reviewed publications were excluded)

The data from the studies that fit the criteria were then tabulated to depict the animal model, injury model, treatment's dose and timing, experimental groups tested in the study, number of animals used (or " $n$ " per group), and reported behavioral and non-behavioral outcomes (e.g., histologic, biochemical, or physiologic outcomes). A summary statement about the body of literature was then generated.

\section{Results}

Using this selection process, we identified the following therapies: chondroitinase $\mathrm{ABC}$, anti-Nogo approaches, and Rho antagonists (Table 1). The PubMed searches on these therapies were initially conducted in the spring/summer of 2008 by SCI researchers across Canada and an updated search was conducted in June 2009. By applying the previously described criteria (essentially, in vivo animal studies utilizing a traumatic model of spinal cord injury), the following studies were generated, and the tables for each of these respective therapies are listed below.

\section{Chondroitinase $A B C$}

This systematic review revealed 23 studies, which utilized chondroitinase $\mathrm{ABC}(\mathrm{ChABC})$ in an in vivo model of SCI

Table 1. Directly Applied Biologic Therapies

\begin{tabular}{llc}
\hline Therapy & Mode of administration & $\begin{array}{c}\text { Published } \\
\text { studies } \\
\text { meeting } \\
\text { criteria } \\
\text { (no.) }\end{array}$ \\
\hline $\begin{array}{l}\text { Chondroitinase ABC } \\
\text { Anti-Nogo approaches Intrathecal application } \\
\text { Anti-Rho approaches }\end{array}$ & $\begin{array}{l}\text { Direct injection into cord } \\
\text { or extradural application } \\
\text { (e.g., Cethrin) }\end{array}$ & 25 \\
& 94 \\
\hline
\end{tabular}

(Table 2). As would be expected, the majority of studies involved the use of the rat species, although one mouse model (Carter et al., 2008) and one cat model (Tester and Howland, 2008) were tested as well. The injury models typically were that of "sharp" or "crush" injuries, such as a hemisection, over-hemisection, transection, dorsal crush, or forceps compression, reflecting the mechanism of action of ChABC and the desire to measure axonal sprouting/growth in response to it. Two studies employed an NYU impactor for a thoracic contusion injury (Ikegami et al., 2005; Iseda et al., 2008). Notably, Iseda and colleagues (2008) actually compared ChABC in both a contusion and a hemisection model and reported that $\mathrm{ChABC}$ promoted sprouting only in the hemisection, but not the contusion, SCI model.

The majority of injuries occurred in the thoracic spine, although eight of the 24 articles employed cervical injury models. The mode and timing of administration in this series of articles varied substantially. The ChABC was typically either injected directly into the cord at various depths and distances from the injury site or delivered via intrathecal injection/infusion. The dosing regimen ranged from immediate, single application (e.g., Tan et al., 2006; Yick et al., 2003, 2004) to continuous infusion over many weeks (e.g., Massey et al., 2008).

A number of researchers have described the use of ChABC as a supplement to a cell transplant therapy such as Schwann cells, olfactory-ensheathing glia, peripheral nerve transplants, fetal cells transplants, or neural precursor cells (Chau et al., 2004; Fouad et al., 2005, 2009; Houle et al., 2006; Ikegami et al., 2005; Vavrek et al., 2007). The inclusion of these studies in this table could be debated as the ChABC was utilized as an adjunct (and by itself these are less informative about the therapeutic applicability of $\mathrm{ChABC}$ as a stand-alone therapy). Nonetheless, we include them here as they fulfilled the basic criteria of being in vivo assessments within a traumatic SCI model.

In keeping with the interest in ChABC's putative mechanism of action, 13 of the 24 studies were solely focused on anatomical/histologic outcomes, with no measurement of behavioral outcome (Carter et al., 2008; Chau et al., 2004; Fouad et al., 2009; Iaci et al., 2007; Ikegami et al., 2005; Iseda et al., 2008; Massey et al., 2006, 2008; Shields et al., 2008; Tan et al., 2006; Tom and Houlé, 2008; Vavrek et al., 2007; Xia et al., 2008; Yick et al., 2003). In general, independent laboratories report $\mathrm{ChABC}$ promoting increased axonal sprouting (particularly serotonergic fibers) using either anterograde or retrograde tracing techniques. As an adjunct treatment to a transplantation therapy (e.g., Schwann cells, peripheral nerve graft), ChABC reportedly improved axonal growth and/or serotonergic sprouting (Chau et al., 2004; Fouad et al., 2005; Houle et al., 2006; Shields et al., 2008; Tom and Houlé, 2008). Xia and colleagues (2008) reported a reduced cystic cavity, suggestive of some neuroprotective effect. Carter and colleagues (2009) reported the prevention of neuron atrophy in the cortical regions that contained CSNs projecting to the thoracic spinal cord. In the same article, the effect on the intracellular signaling was demonstrated.

As for behavioral outcomes, the use of cervical injury models by a number of authors allowed for the assessment of forelimb functional recovery. In the cervical injury models, evidence for improvements in forelimb function with ChABC was modest. While Yick and colleagues (2004), Houle and 


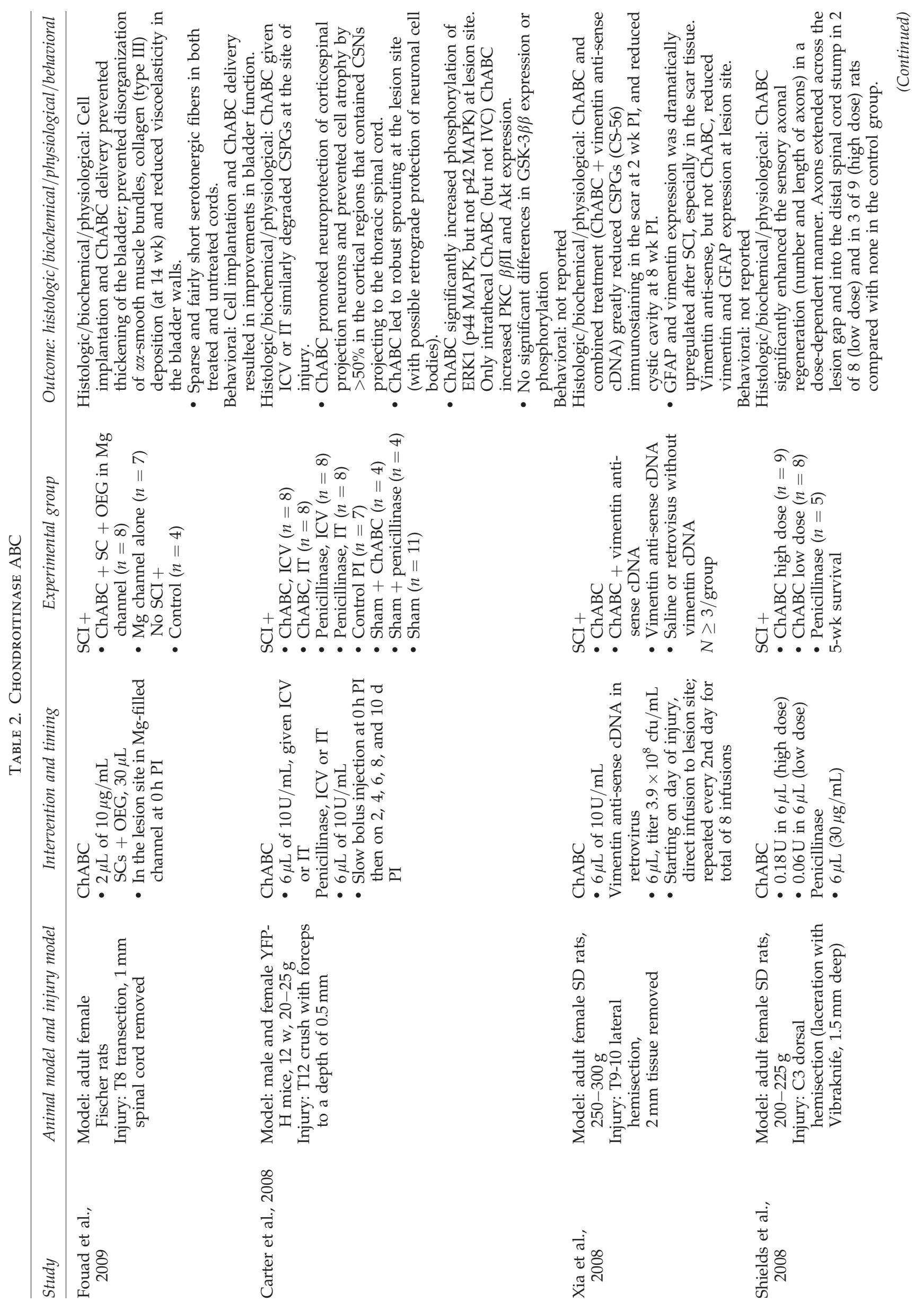




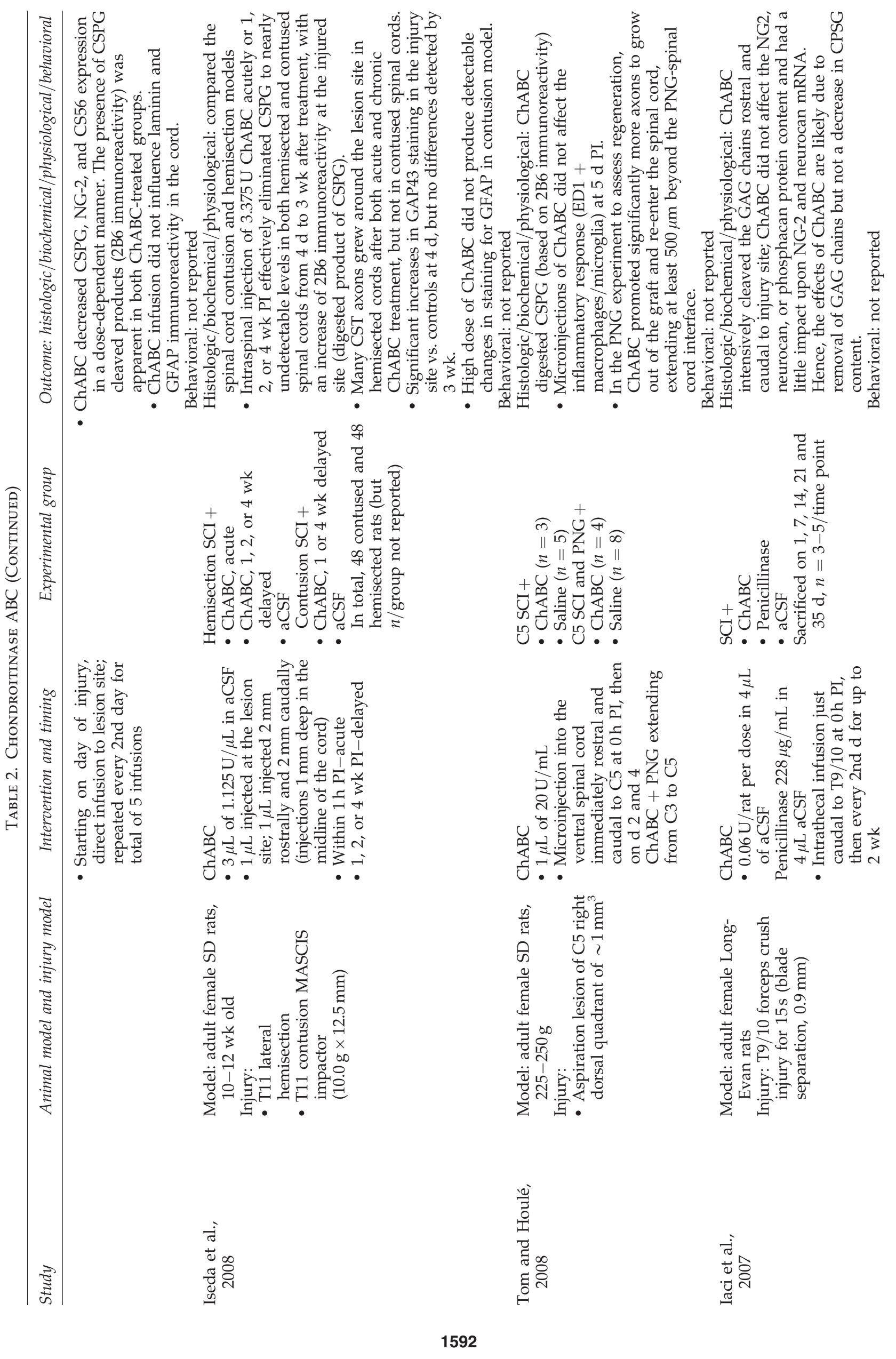




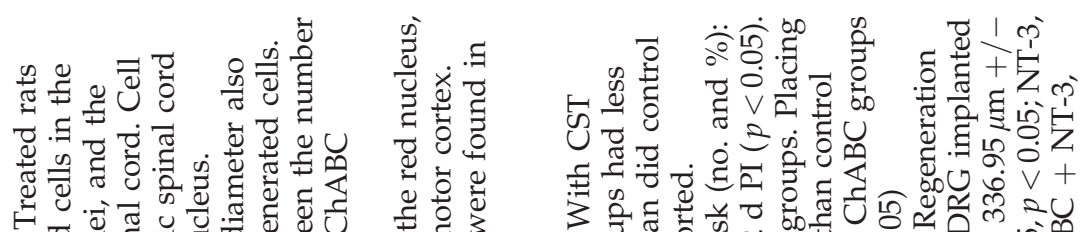

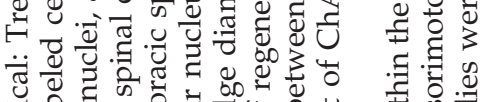

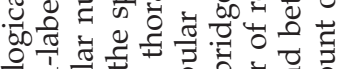

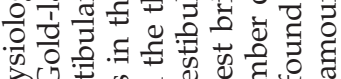

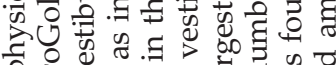

(t)

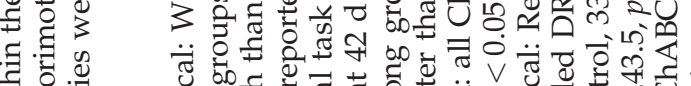

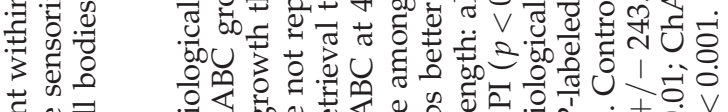

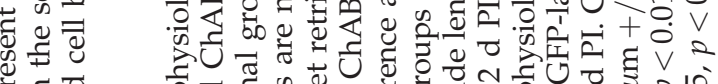

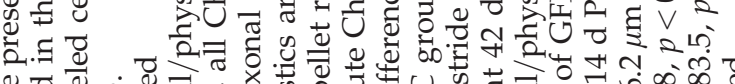

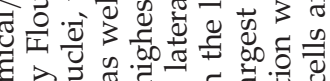

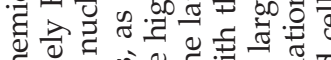

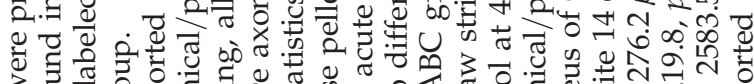
U⿴囗十)

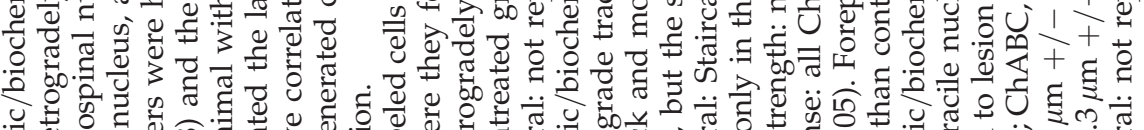

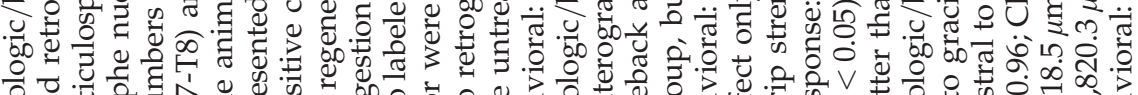

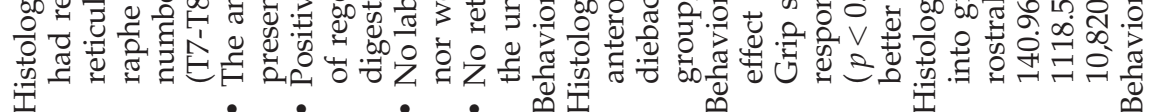

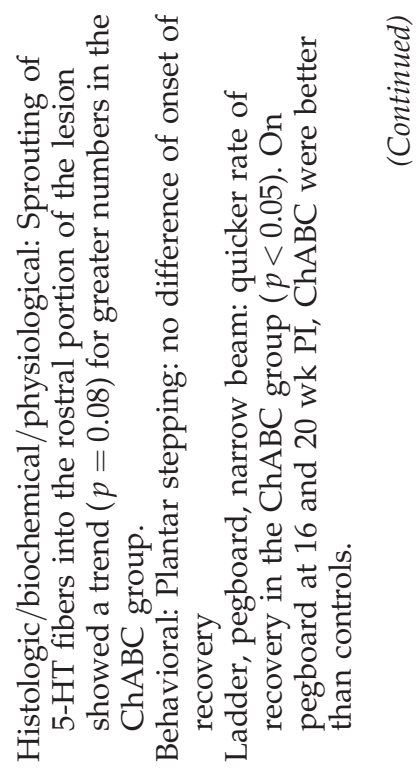

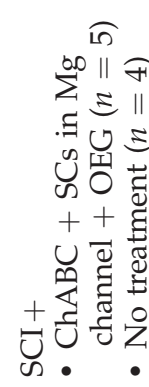
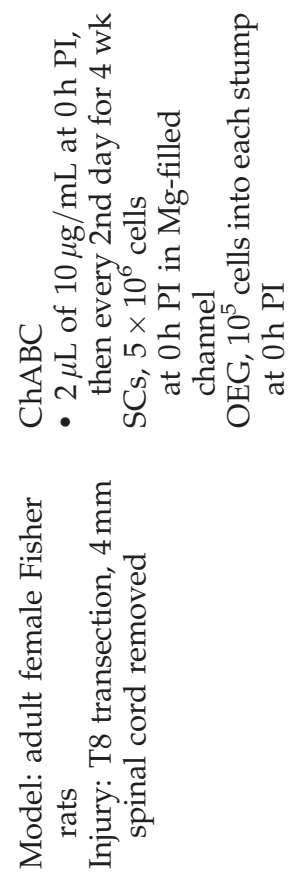

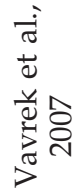

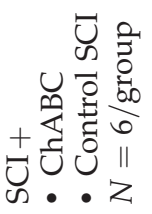

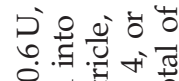

II 表方

है 歪

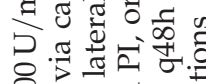

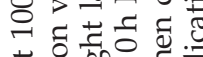

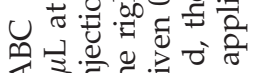

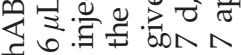

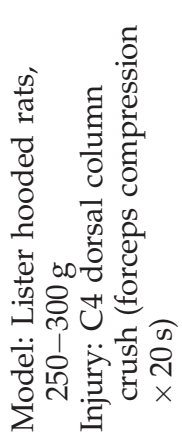

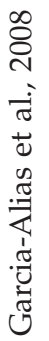
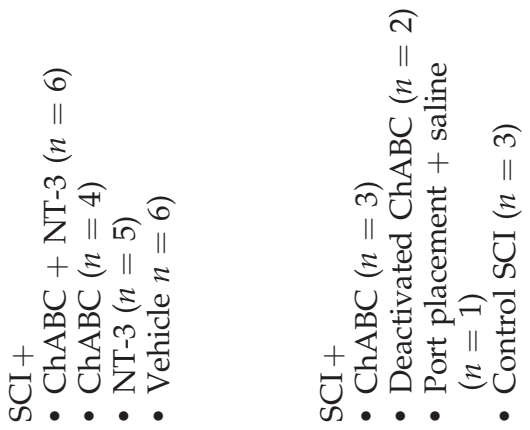

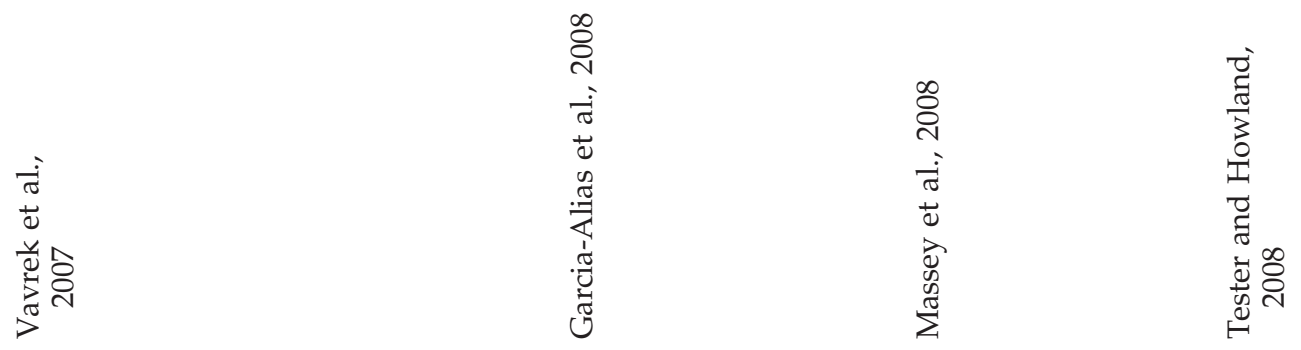




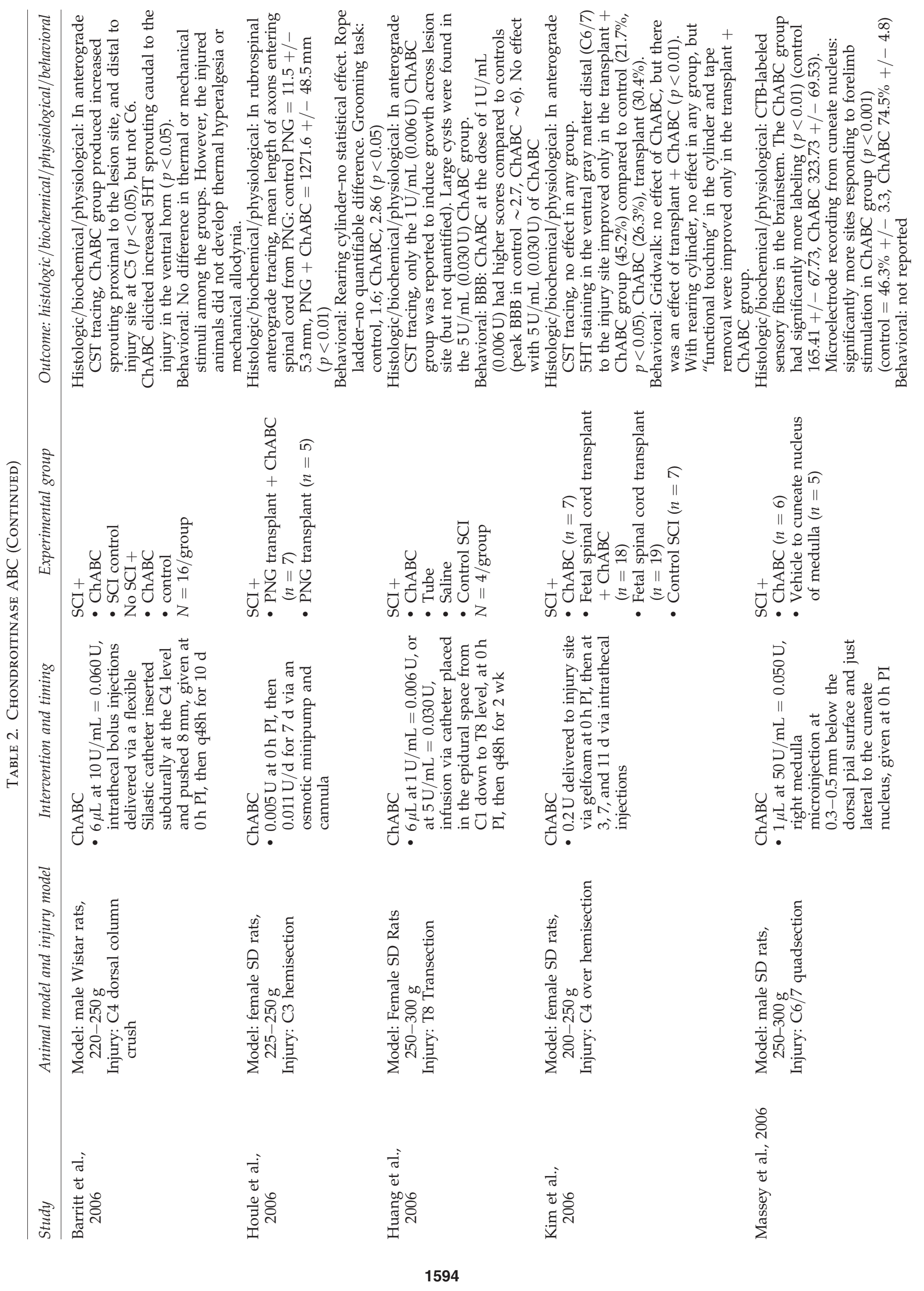




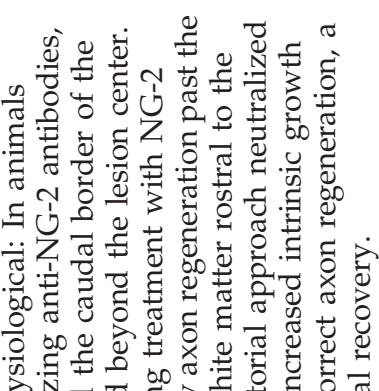

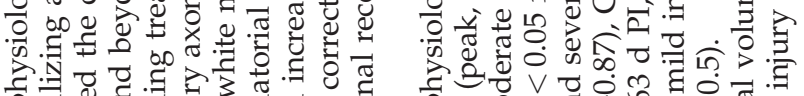

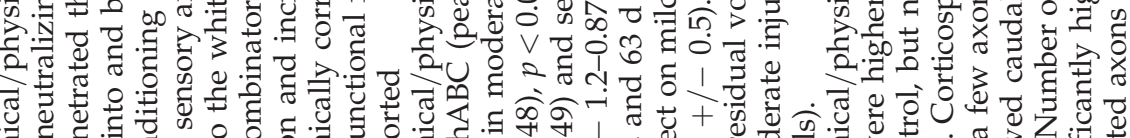

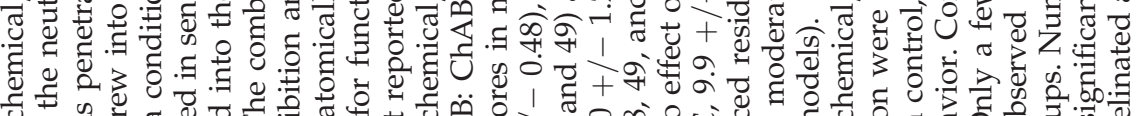

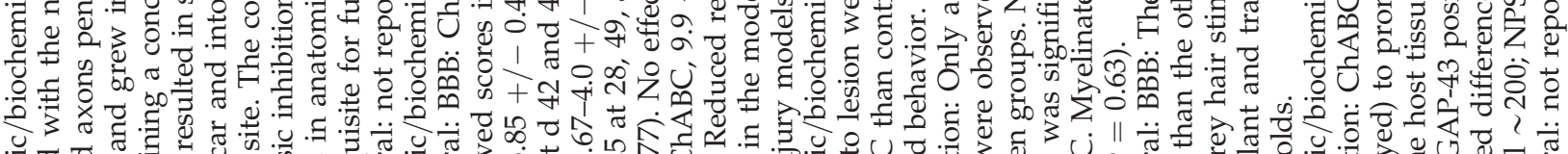

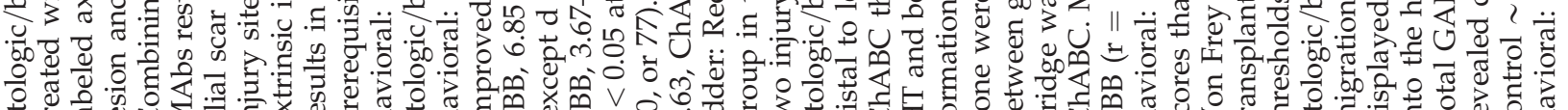

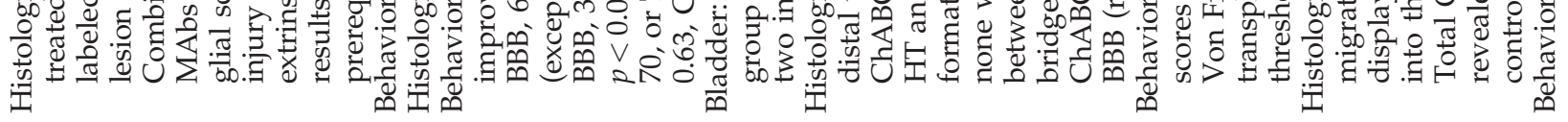
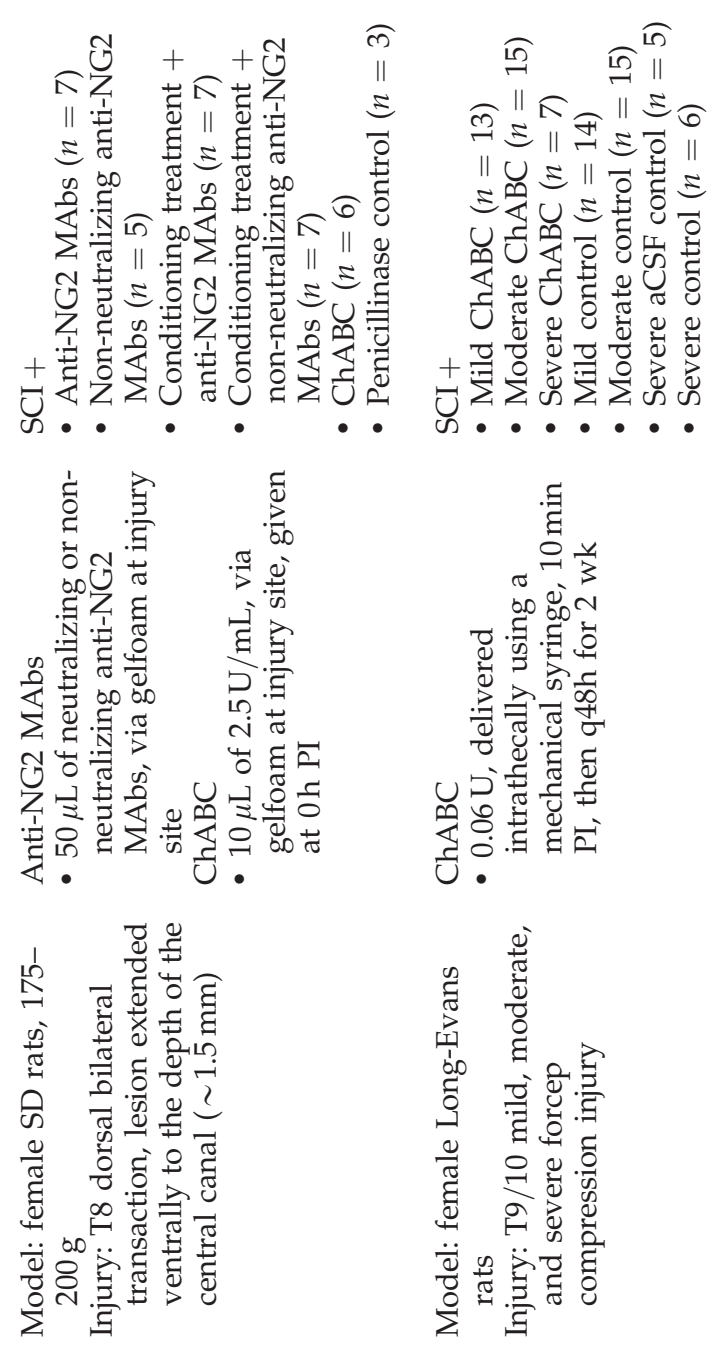

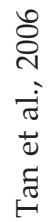
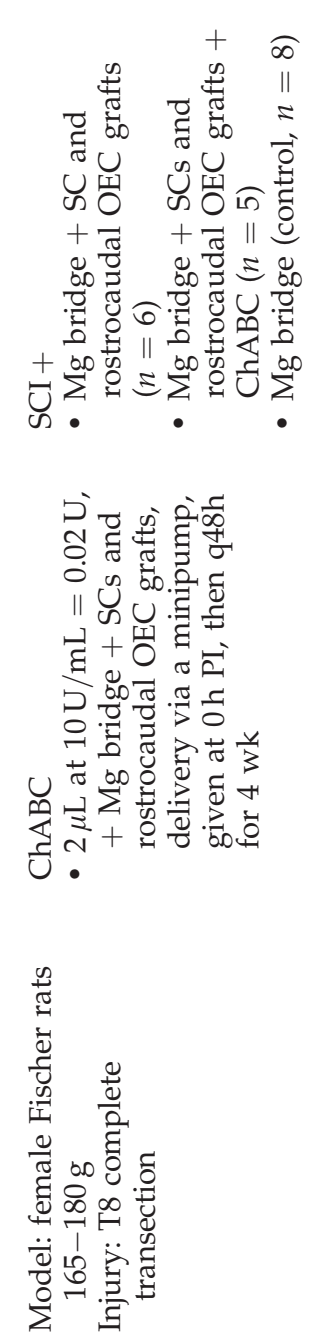

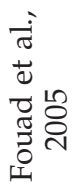
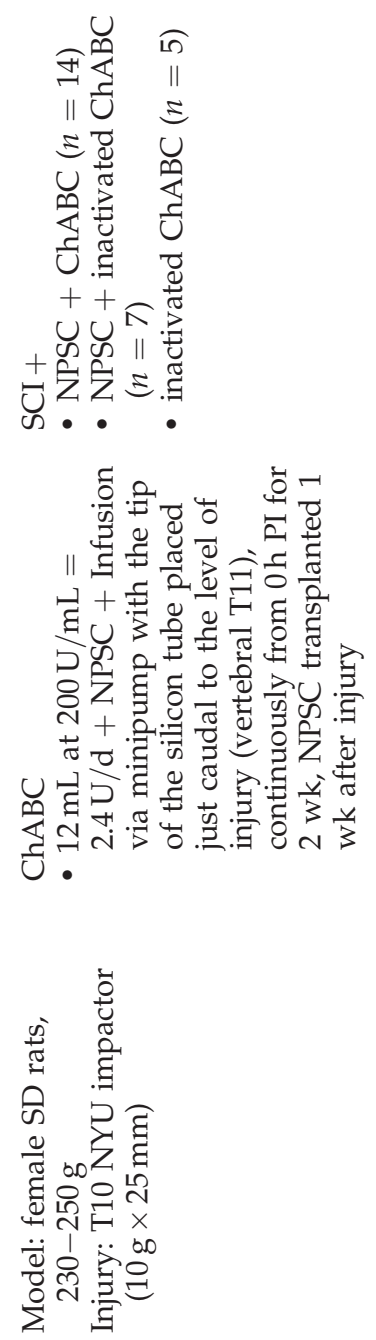

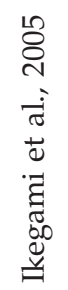




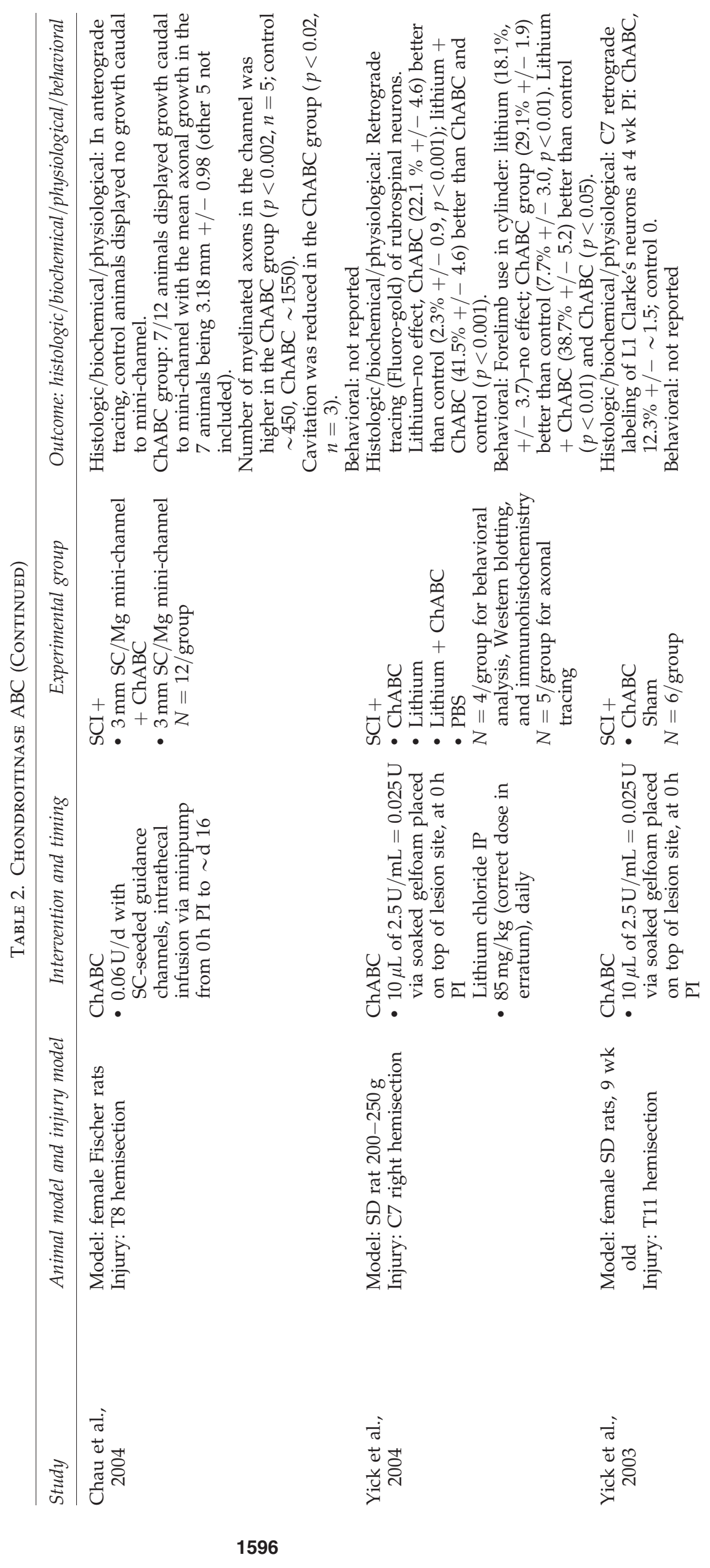




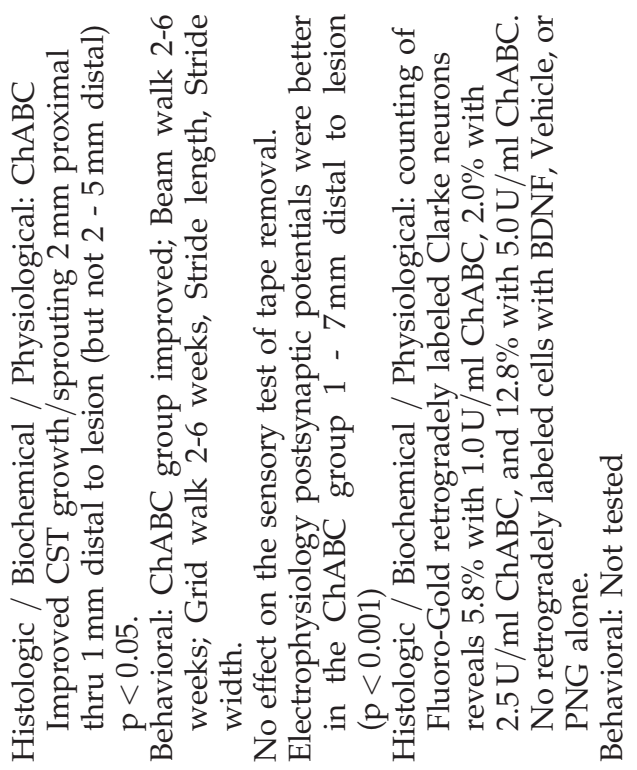

กิ

ำ

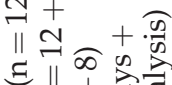

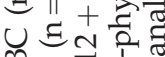

过

㫕芑预.

+ ठ 들 छ

๒ળ

-
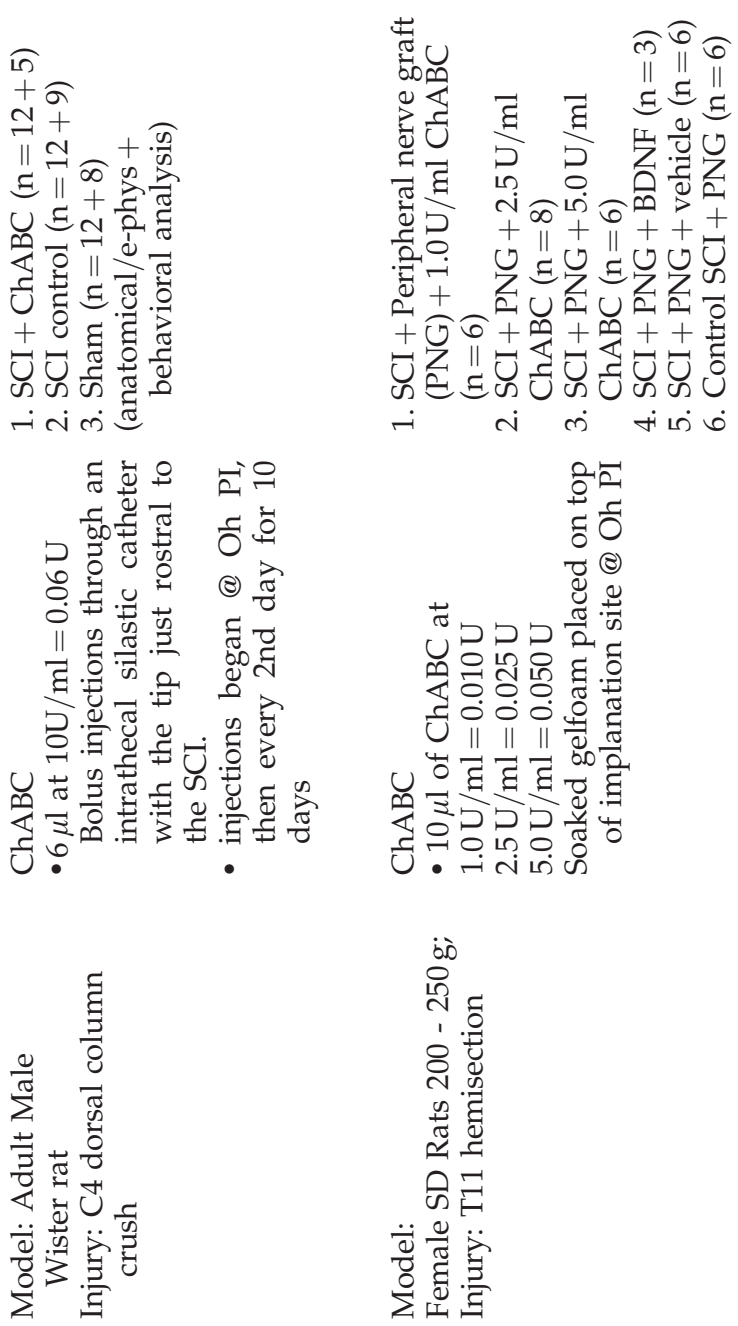

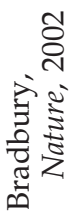
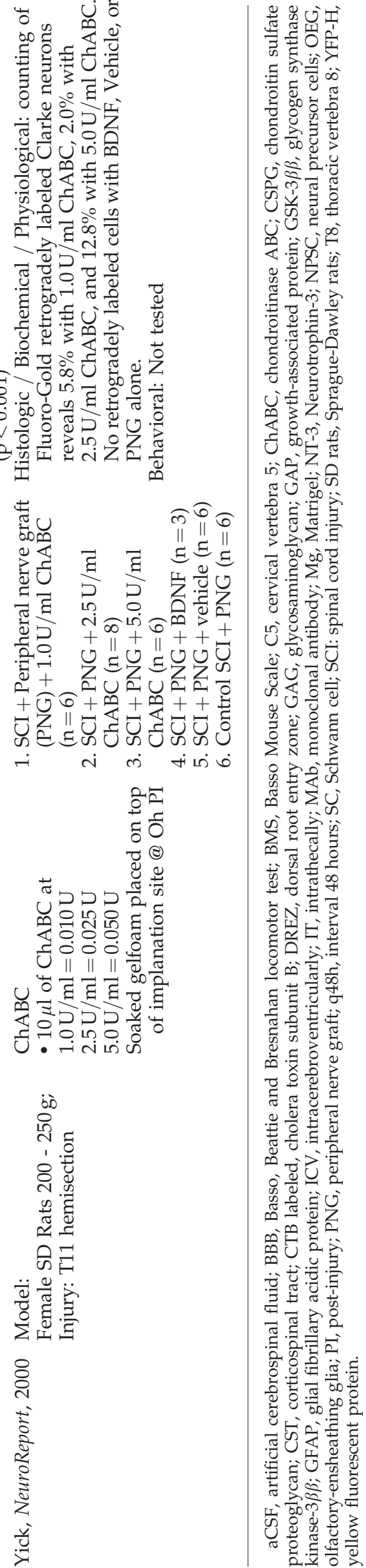
colleagues (2006), and Garcia-Alias and colleagues (2008) reported some improved forelimb performance with ChABC treatment (the latter in a number of metrics), significant improvements with $\mathrm{ChABC}$ alone were not observed by others (Kim et al., 2006). In thoracic injury models, behavioral recovery with $\mathrm{ChABC}$ treatment alone was found to be modest in some studies (Caggiano et al., 2005; Huang et al., 2006; Tester and Howland, 2008), while others described no improvements (Barritt et al.). Fouad and colleagues (2009) reported the positive effects of ChABC on bladder function and morphology. In combination with a cell transplant therapy, behavioral recovery was greater when the transplant was combined with ChABC than without (Fouad et al., 2006; Kim et al., 2006), suggesting that the ChABC may play an important role as an adjunct therapy for such transplants.

\section{Anti-Nogo approaches}

The approach of targeting myelin inhibition, and specifically what is now known as Nogo and its downstream pathways, is one of the longest-studied therapeutic strategies in SCI, with the first description of the effect of anti-Nogo (IN-1) monoclonal antibody on corticospinal tract sprouting emerging in 1990, nearly 20 years ago. Everything published over the subsequent decade on this strategy came from Dr. Martin Schwab and his colleagues in Zurich as they sought to characterize the effects of this treatment. These studies employed rat and primate species and a sharp partial transection injury (e.g., dorsal hemisection, over-hemisection, unilateral pyramidotomy) of the thoracic or upper cervical spine, with an IN-1 secreting hybridoma implanted into the dorsal frontro-parietal cortex typically at the time of spinal cord injury. Many of these studies examined histologic outcomes exclusively, with a focus on whether the IN-1 antibody was stimulating axonal regeneration/sprouting (which typically it was). Behavioral outcomes were also improved in some studies. Certainly, there was compelling evidence from this single laboratory to support the promise of the IN-1 antibody therapy, providing a rationale to pursue the translation of this approach.

With the cloning of Nogo in 2000, the strategy surrounding this aspect of myelin inhibition has evolved into different approaches. The IN-1 monoclonal antibody approach (which involved the transplant of a hybridoma secreting IgM antibody) has been supplanted by an intrathecally applied antiNogo IgG antibody approach, which has now entered clinical trials. This intrathecally applied anti-Nogo IgG treatment has been tried in both rat and primate SCI models, with immediate post-injury administration leading to both anatomic and functional improvements (Freund et al., 2006, 2007, 2009; Liebscher et al., 2005; Wannier-Morino et al., 2008). This antiNogo IgG intrathecal approach has been translated into human clinical trials, with a European and Canadian trial being initiated in 2007 .

Another approach being developed by Dr. Stephen Strittmatter and his colleagues at Yale University is the competitive antagonism of the Nogo receptor with a synthetic Nogo-66 (1-40) peptide (Nogo extracellular peptide, residues 1-40), otherwise known as "NEP1-40" or "Nogo-66 receptor antagonist peptide." This has been applied both intrathecally and systemically (via subcutaneous injection) in mouse and rat studies utilizing both cervical and thoracic partial transection spinal cord injury models. In this acute treatment paradigm, NEP1-40 has been reported to promote both histologic improvements (i.e., enhanced sprouting/regeneration), and modest behavioral improvements (Atalay et al., 2007; Cao et al., 2008; Grandpre et al., 2002; Li and Strittmatter, 2003). It has also been reported by $\mathrm{Li}$ and Strittmatter (2003) to be effective in a subacute treatment paradigm with a 7-day delay post-injury prior to intervention. Steward and colleagues (2008) attempted to reproduce these findings with NEP1-40 in an NIH-funded replication study, and while there was a weak suggestion that NEP1-40 "created a situation that was slightly more conducive to axon regeneration," the robust sprouting/regeneration and improved behavioral recovery reported by $\mathrm{Li}$ and Strittmatter were not observed.

An additional approach, also pioneered by Strittmatter and colleagues, is the use of a soluble Nogo receptor ectodomain, which has been administered intrathecally at the time of injury in rodent thoracic contusion and partial transection models (Li et al., 2004; Wang et al., 2006). In both cases, there was improved behavioral recovery. In the study by Wang and colleagues (2006), a 3-day delay in treatment did not nullify the behavioral improvements.

Measured within the context of the SCI research community, the pre-clinical body of work behind the anti-Nogo approaches is considerable (Table 3). There are good examples of treatments that have been extensively studied, but the majority of investigation has resided within single laboratories. The significant benefits of NEP1-40 (Li and Strittmatter, 2003) were not observed in a formal, NIH-funded replication study (Steward et al., 2008), suggesting the need for further investigation to characterize the robustness of this intervention. The anti-Nogo antibody treatment has not undergone a similar replication study, although commercial intellectual property issues will likely preclude such an investigation. A recent study that evaluated the corticospinal tract after a dorsal hemisection injury in two different Nogo-deficient mutant mouse lines found enhanced regeneration in neither (Lee et al., 2009). Interpreting the implications of such negative findings in this loss-of-function experiment with the positive findings from Dr. Schwab's laboratory with the administration of anti-Nogo antibodies is difficult given the obvious differences in experimental paradigm.

\section{Rho antagonists}

The Rho pathway is recognized as an important biochemical signaling pathway in growth cone dynamics and neuronal apoptosis. Inhibition of Rho activation may therefore influence axonal sprouting/regeneration and secondary damage at the injury site. The strategy of inhibiting Rho within in vivo models of SCI has been explored by a number of investigators (Table 4). Dr. Lisa McKerracher and colleagues were the first research group to demonstrate that the application of Rho-kinase inhibitors, Y27632 and C3 transferase, directly to the SCI epicenter immediately after injury could significantly improve behavioral recovery within mice that had received a dorsal over-hemisection experimental lesion (Dergham et al., 2002). This C3 transferase approach was found to reduce RhoA activation after contusive thoracic SCI (Dubreuil et al., 2003).

Interestingly, the experience of others with C3 transferase early on was not similarly positive. Sung and colleagues 


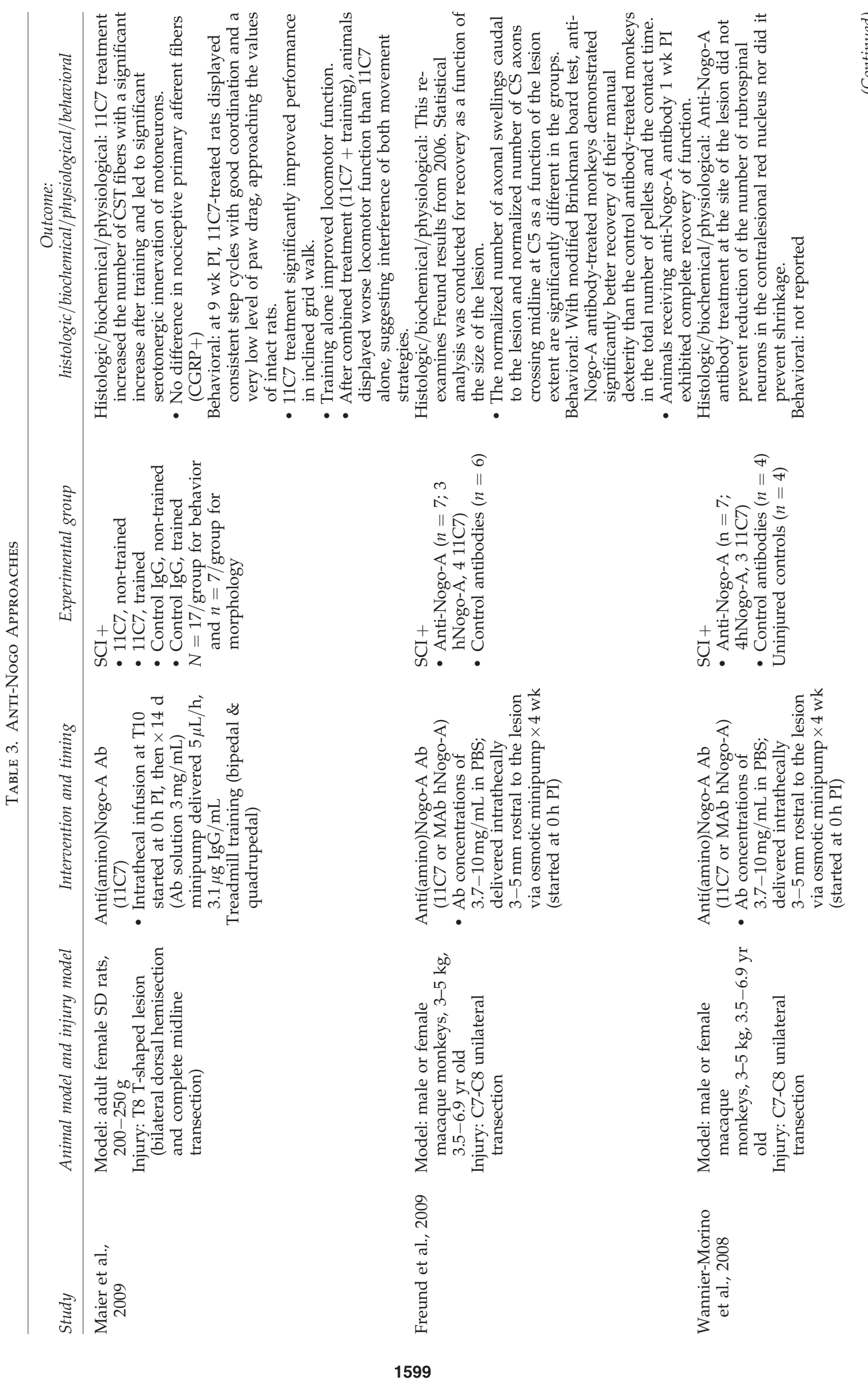




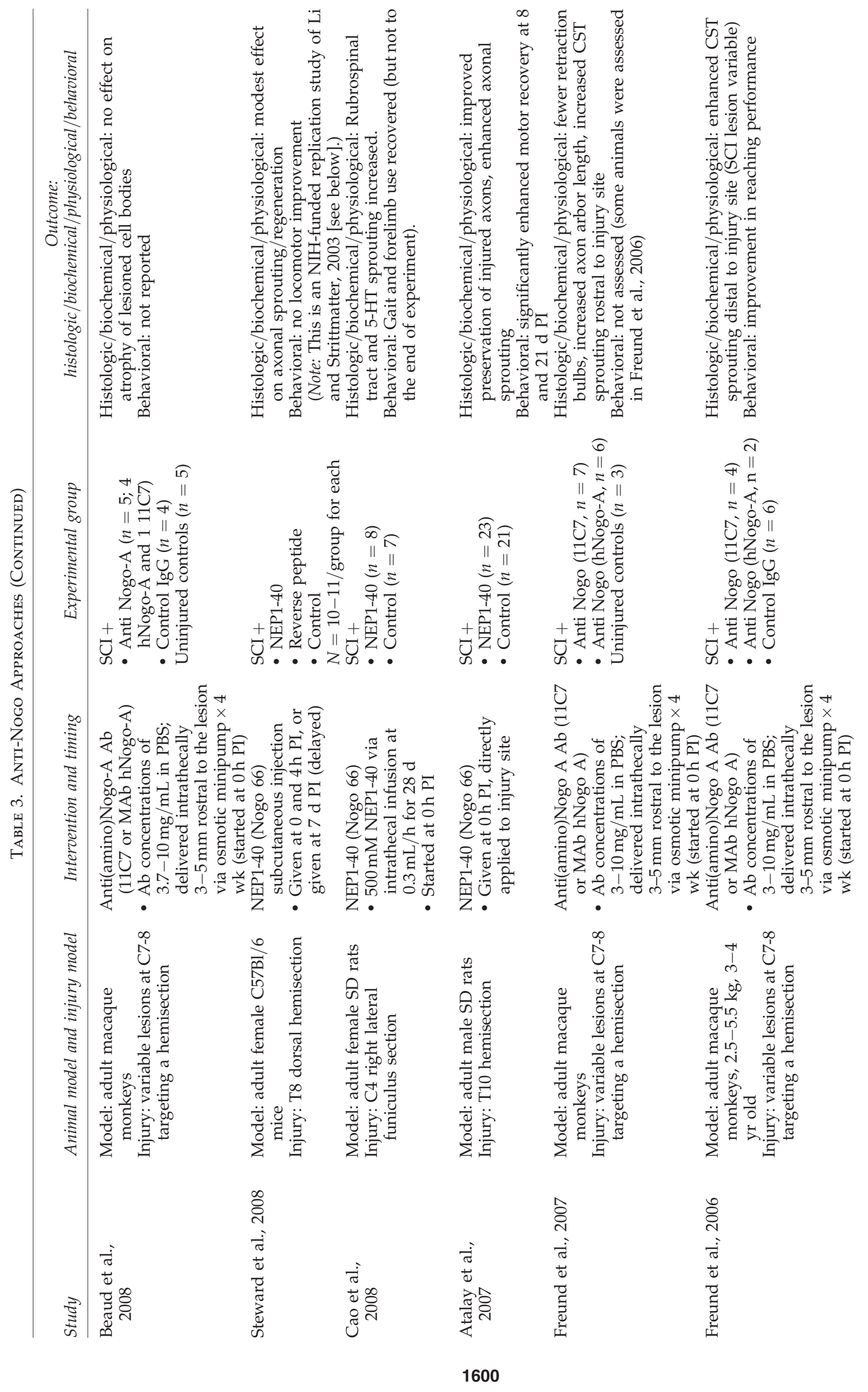



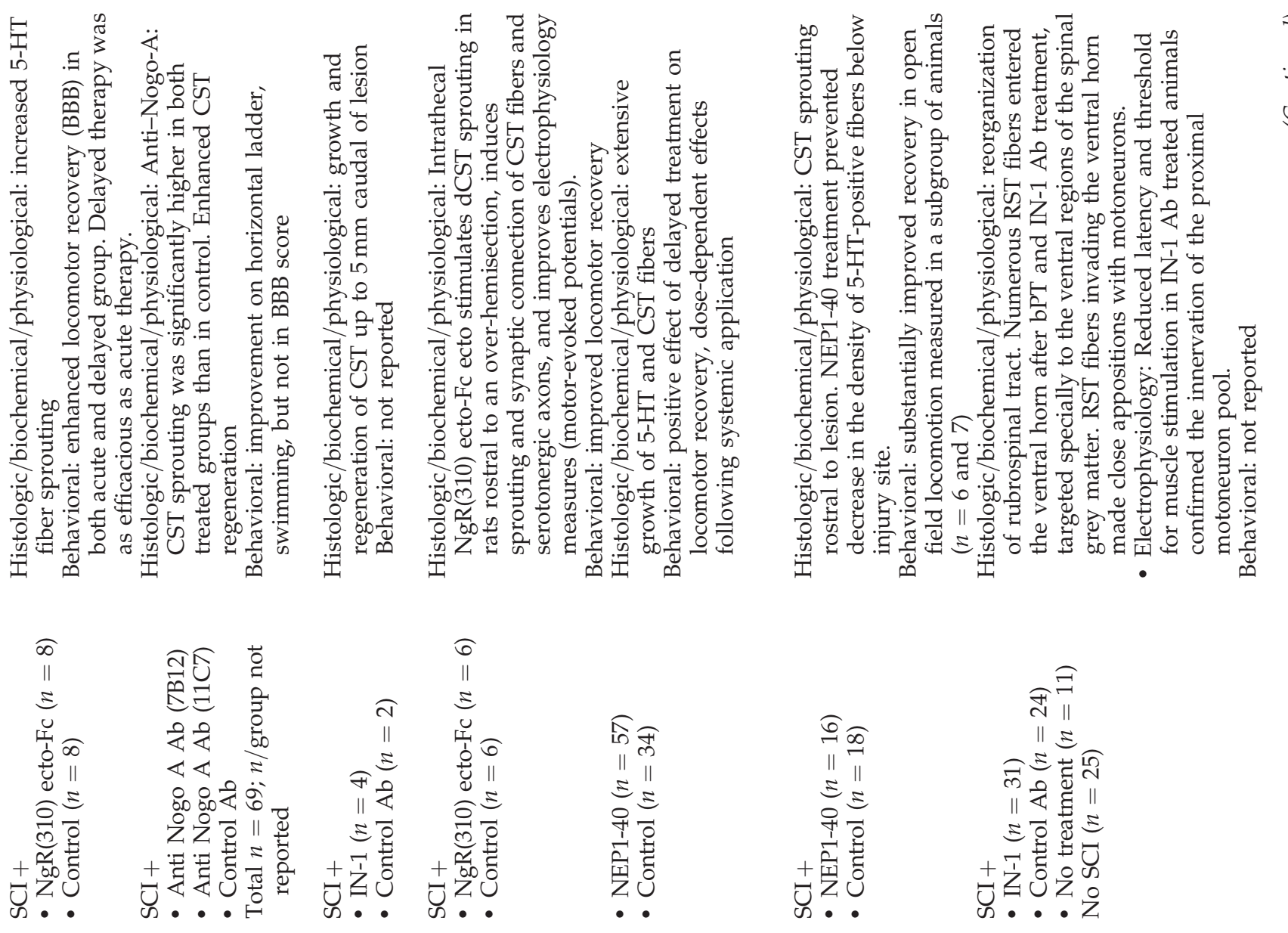

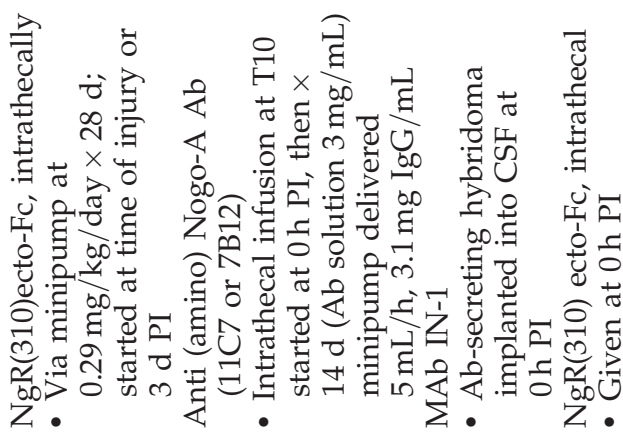
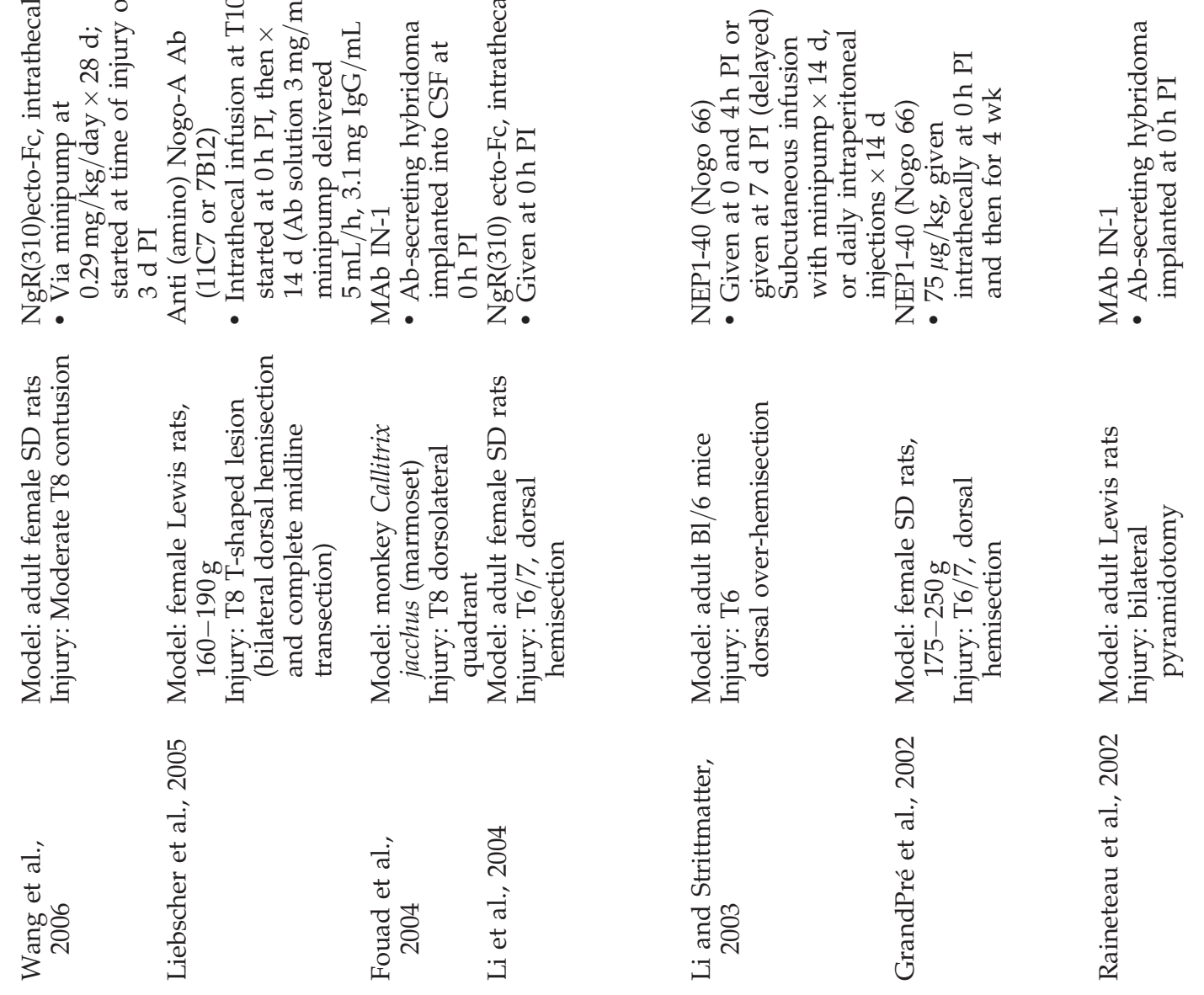

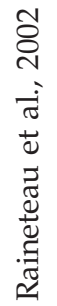




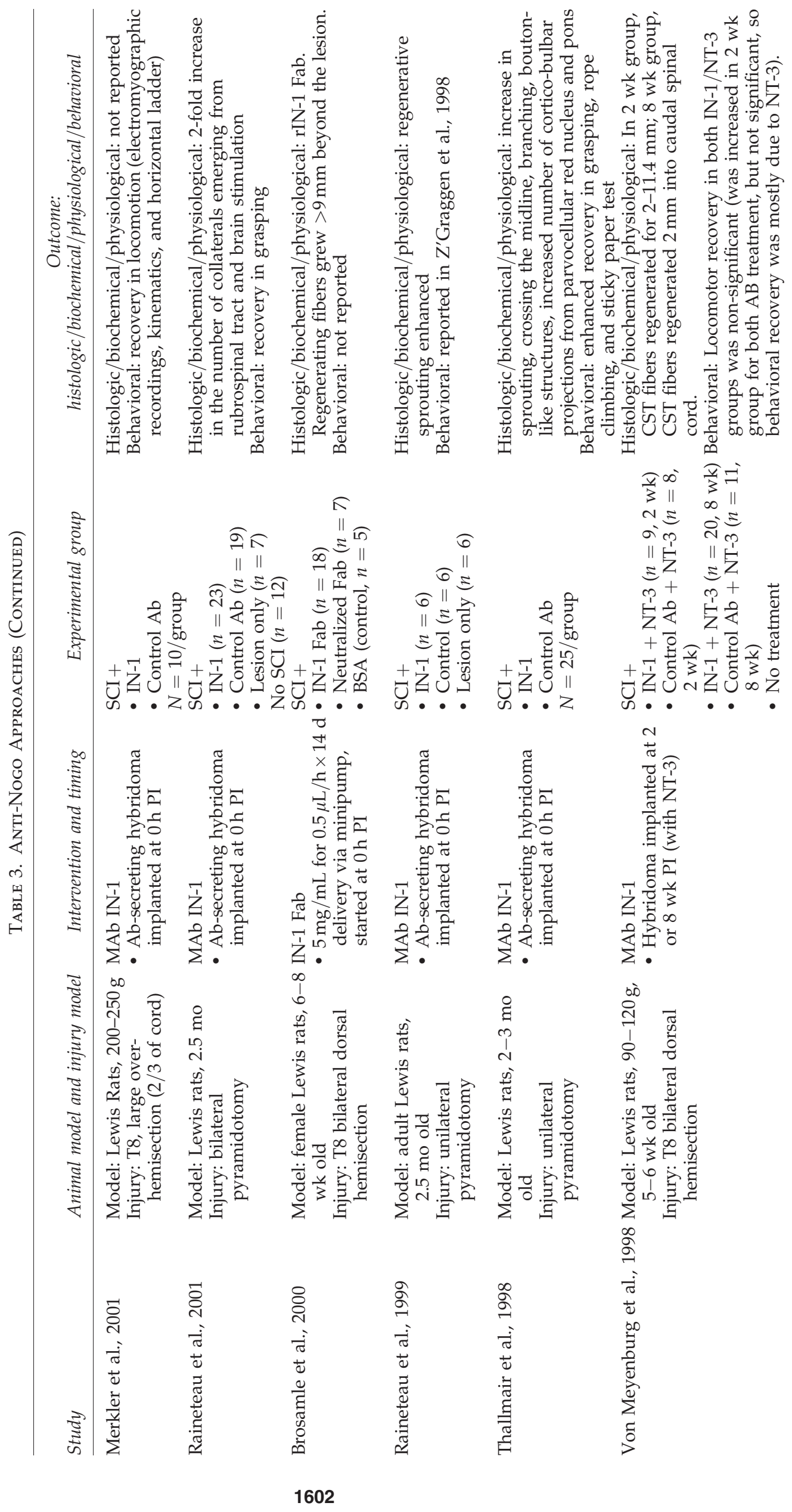



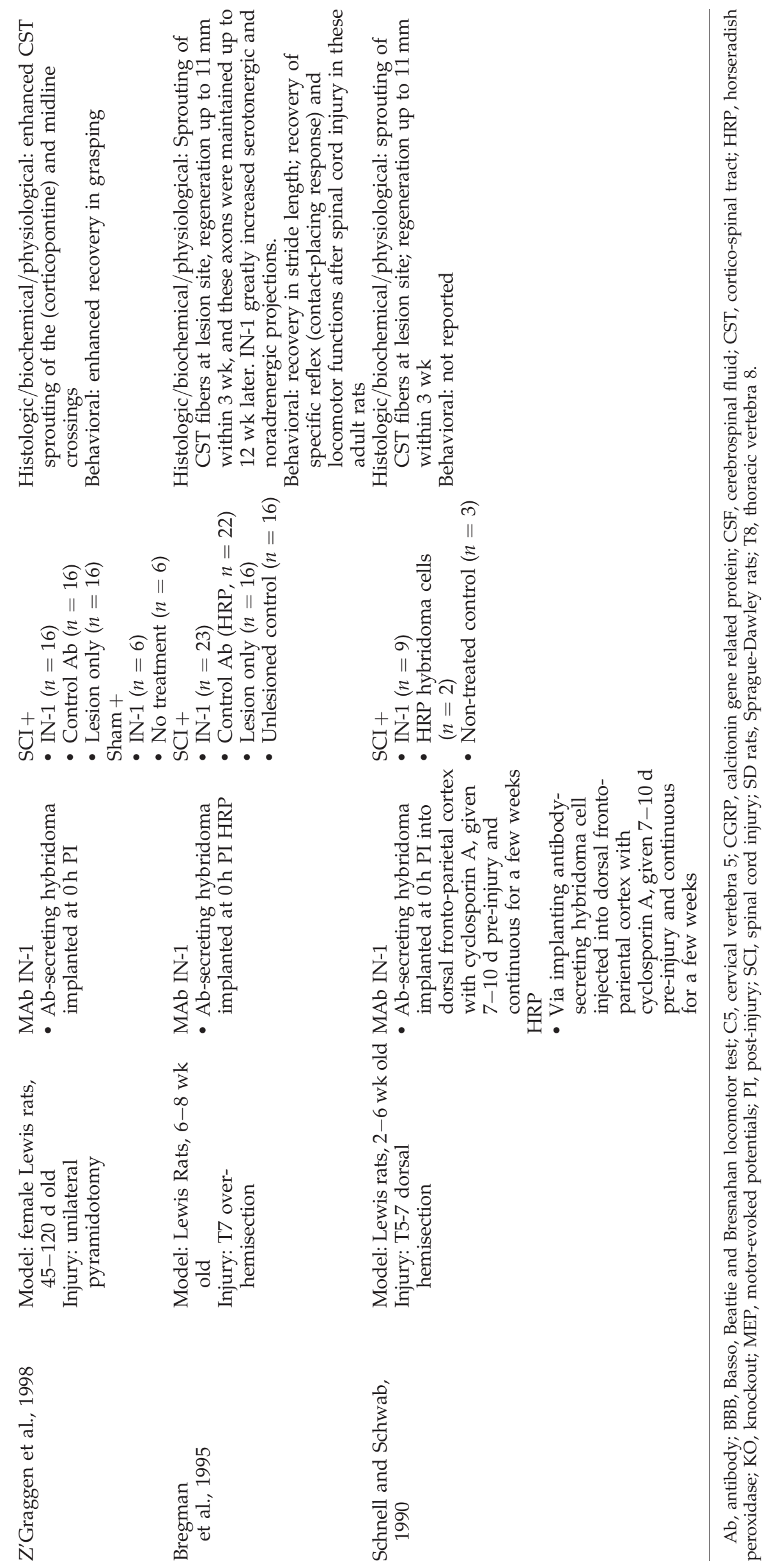


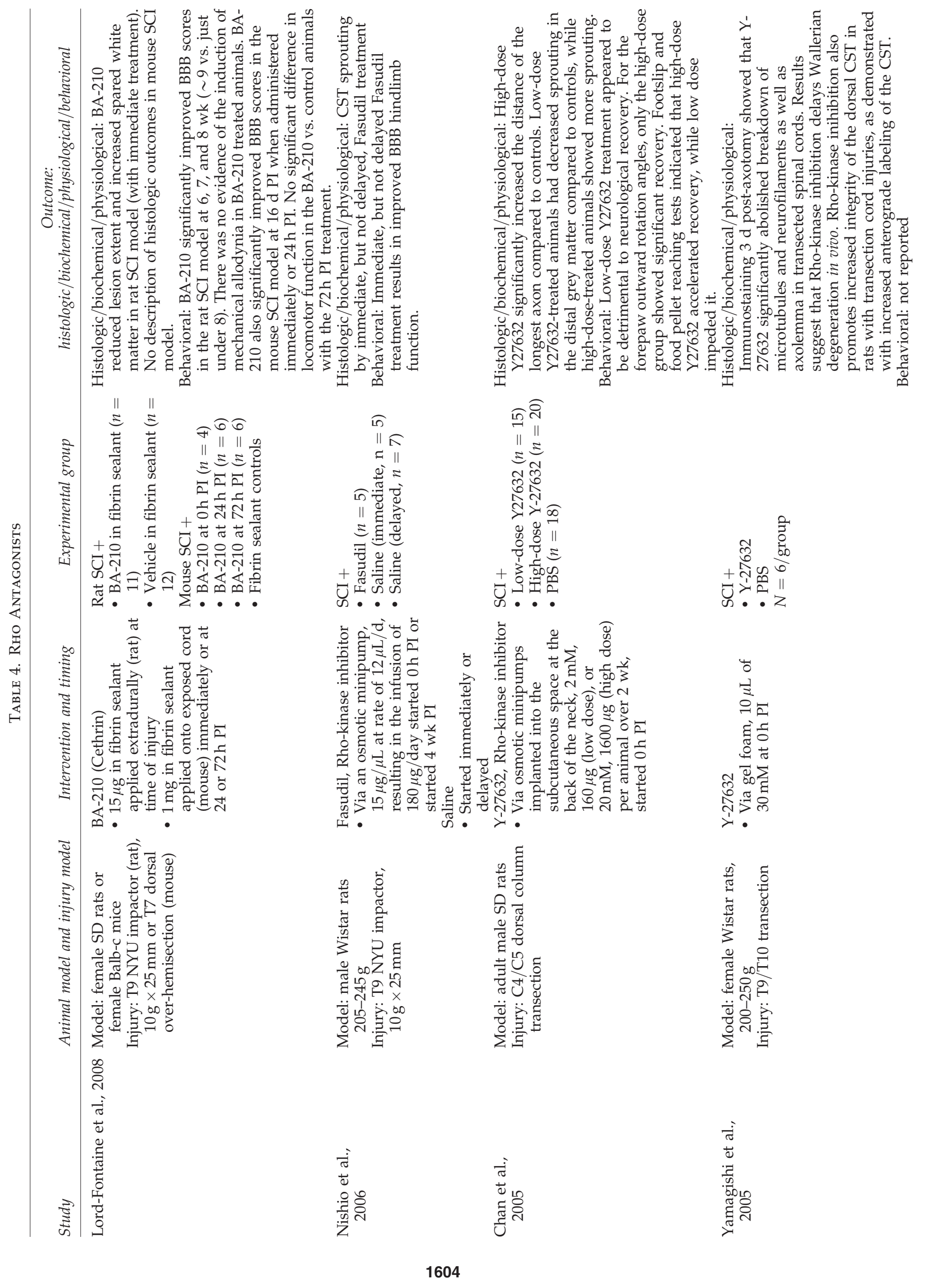




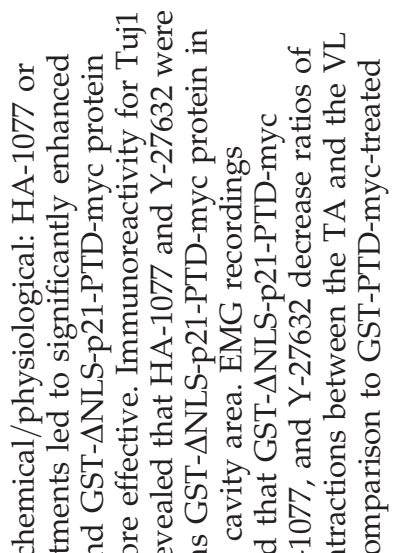

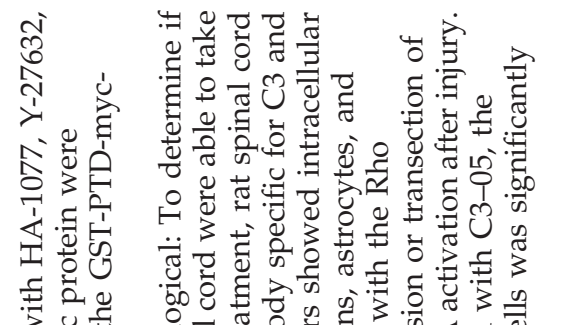

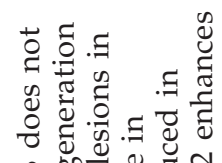

Uి

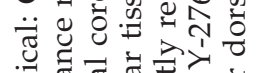

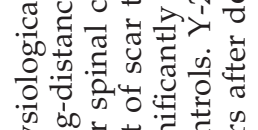

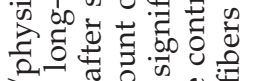

ची

फे

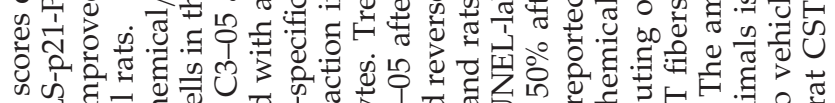

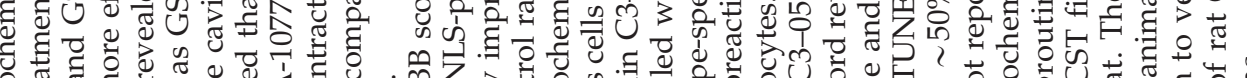

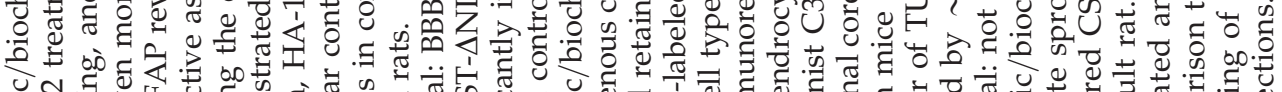

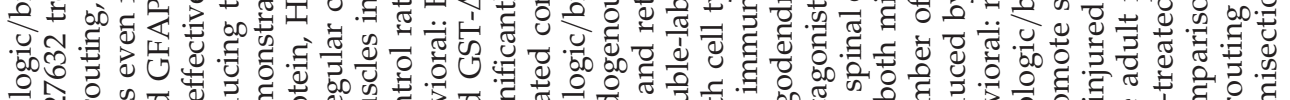

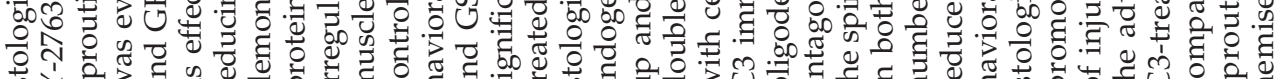
总
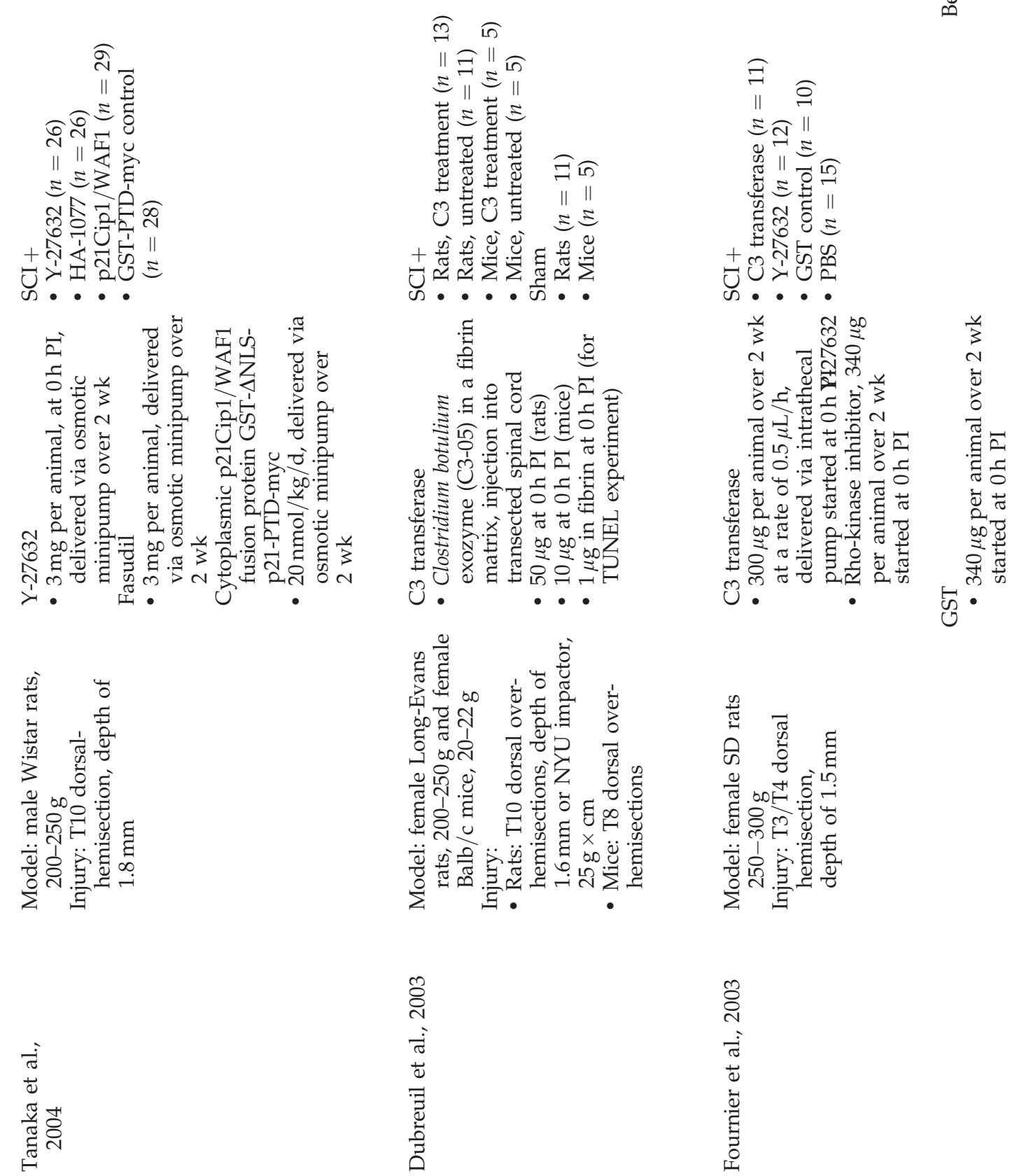

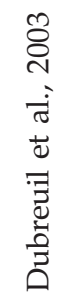

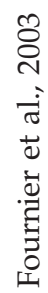




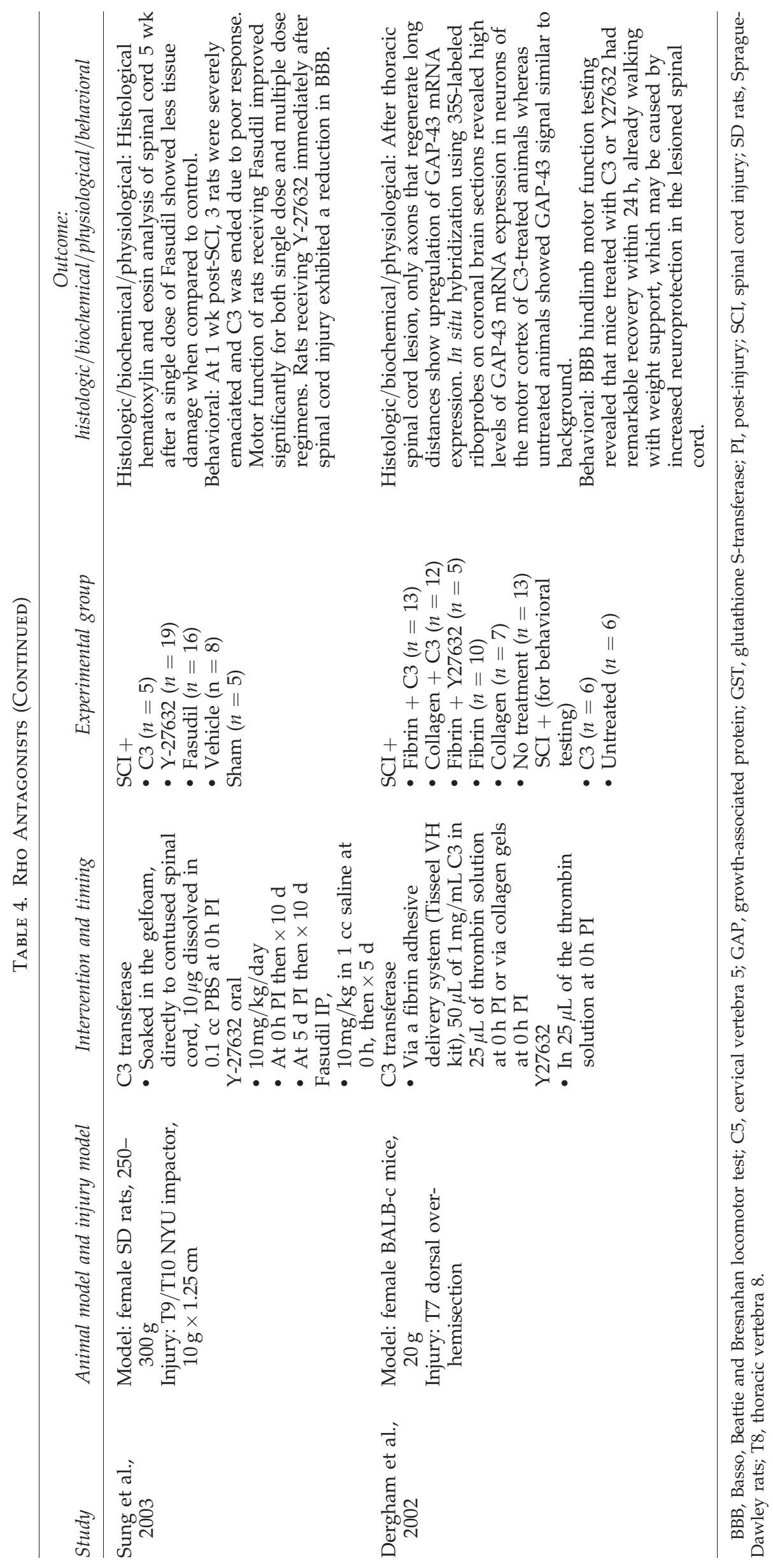


(2003) reported that their C3-treated animals were severely emaciated, and many were terminated. Fournier and colleagues (2003) observed no axonal regeneration/sprouting and delayed hindlimb locomotor recovery, despite significantly reduced scar formation with C3-treated animals compared to fusion protein control-treated animals. Nonetheless, design improvements to create a C3-fusion protein consisting of the $\mathrm{C} 3$ transferase coupled to a transport sequence (i.e., BA-210) facilitate the ability for this biological compound to cross plasma membranes and gain increased distribution throughout the injured spinal cord. This more permeable form of C 3 transferase has been translated into human clinical trials under the name Cethrin ${ }^{\circledR}$ (BioAxone Therapeutique, Montreal, Quebec, Canada). Rights to Cethrin have since been licensed to Alseres Pharmaceuticals (Hopkinton, MA). A recent report by McKerracher's group studied BA-210 in a rodent contusion injury model and examined different time windows of intervention within a mouse hemisection model (LordFontaine et al., 2008). The authors reported improved behavioral outcomes with the BA-210 in both injury models, with an effective time window extending 24-h post-injury.

The other approach that has been studied is that of Y27632, a selective Rho-kinase inhibitor (downstream of Rho). This has been investigated both as an oral drug and as a directly applied agent. In mouse and rat contusion and partial transection models of SCI, this was found to promote behavioral recovery (Dergham et al., 2002; Fournier et al., 2003; Sung et al., 2003; Tanaka et al., 2004). Chan and colleagues (2005) demonstrated that low doses of Y27632 were detrimental to the rodent cord after dorsal hemisection, while higher doses tended to accelerate recovery.

\section{Discussion}

This article reviews three therapeutic approaches, which entail the direct application of a biological therapy to the injured spinal cord or overlying dura; two have already been commercialized and have moved forward into clinical trials (the anti-Nogo antibody trial [Novartis] and BA-210 [Cethrin]). The anti-Nogo antibody approach that evolved from the IN-1 antibody work has been fairly extensively studied, albeit almost exclusively by Dr. Schwab and Novartis. The C3 approach went into clinical trial as BA-210 after the studies of Dergham and colleagues (2002) and Dubreil and colleagues (2003) were reported. At this stage, replication studies of these patented technologies are unlikely to occur, although the NIH-funded replication of the initial NEP1-40 results has demonstrated how difficult it can be to demonstrate the robustness of the effect.

The fact that these therapies involve some form of direct application to the spinal cord influences their clinical translation in a number of ways. For one, the main target of these agents is to promote axonal growth/sprouting/plasticity by altering the inhibitory SCI environment or the response of axons to this environment. Yet most of the agents are tested in an acute injury paradigm with immediate application at the time of injury, and hence, sorting out the behavioral responses attributable to axonal growth versus those attributable to some form of neuroprotection is difficult. This was, for example, quite evident in the study by Dergham and colleagues (2002), where improved behavioral recovery was seen almost immediately after injury and would therefore be difficult to attribute to the promotion of axonal regeneration. The subsequent study by Dubreuil and colleagues (2003) pointed out that RhoA activation occurred locally at the site of injury after acute SCI and suggested a mechanism by which immediately applied C3 transferase (and also BA-210, or Cethrin) might have a neuroprotective effect. Conceivably, the anti-Nogo and ChABC approaches may be expected to have some additional neuroprotective effect in the rodent spinal cord as well, given that they are administered very early after injury in these preclinical studies.

From the patients' perspective, it matters little whether improved function is related to some form of neuroprotection or some effect on axonal growth. However, at a translational and operational level, the distinction between neuroprotection versus neuroregenerative mechanisms has substantial relevance, given that the need to directly apply these treatments to the exposed spinal cord or dura imposes significant practical challenges to the translation of these therapies. The time delay may be significant before such treatments can be then applied to an acutely injured patient, owing to transport time and availability of imaging and operating room facilities. So if it is indeed a neuroprotective mechanism of action that is being sought, the direct application to the spinal cord clearly has some limitations with respect to how quickly the therapy can be instituted. Incorporating that inherent delay in clinical treatment into experimental pre-clinical studies is simple enough (one just waits before applying the therapy); more difficult is taking the time window of intervention in human studies and extrapolating that to rodent studies (and vice versa). How similar or different the temporal pattern of relevant biological processes is between rodents and humans is unclear, although work by Dr. Lynne Weaver and colleagues would suggest that the time course of cellular invasion into the injured cord is reasonably similar between the two (Fleming et al., 2006). Irrespective of this, when reviewing the studies included in these tables, one cannot help but feel that more pre-clinical studies with delays of intervention are needed. In 21 of $23 \mathrm{ChABC}$ studies, 22 of 24 anti-Nogo studies, and 8 of 9 anti-Rho studies (i.e., 91\% of all studies), the intervention was applied immediately after the injury was induced.

The other important consideration in the translation of these directly applied biologic therapies is their biodistribution within the injured spinal cord. It is difficult to ascertain the degree and kinetics of the agents' distribution into the spinal cord, either via diffusion through the cerebrospinal fluid within the intrathecal space (e.g., anti-Nogo antibodies) or diffusion through the dura and then across the CSF (e.g., BA-210). For example, in most ChABC studies, a sharp partial transection model is employed (hence opening up the dura), and then the ChABC is directly injected into and/or infused onto the cord. How to translate the findings of such studies into a clinically relevant therapeutic paradigm is not clear. Similarly, partial transection injuries have been used for most anti-Nogo studies, so determining what the biodistribution of the antibody within a contused spinal cord is unclear. Finally, for an extradural application of a protein such as Cethrin, while the biodistribution in a rodent model of cord injury may be acceptable (where the CSF space is very small), how such a protein distributes to the injured human spinal cord when it must diffuse through a substantial amount of CSF is unknown. These are all important considerations for such directly applied therapies. 
In summary, in this article we systematically reviewed the preclinical animal model data on ChABC, anti-Nogo approaches, and anti-Rho approaches. The question of whether any one of these approaches is ready for human translation has already been answered to some extent, as both the anti-Nogo antibody and the Rho antagonist Cethrin are well into clinical trials. Despite this, there remain questions about the time window of applicability and the biodistribution of these agents within the injured cord. Further pre-clinical work on these therapies is warranted in order to refine and optimize the treatment paradigms for human study.

\section{Acknowledgments}

This work was supported by the Rick Hansen Institute (formerly The Canadian SCI Solutions Network). BKK holds a CIHR New Investigator Award, and WT is the Rick Hansen Man in Motion Chair of Spinal Cord Injury Research.

\section{Author Disclosure Statement}

No conflicting financial interests exist.

\section{References}

\section{Chondroitinase $A B C$}

Barritt, A.W., Davies, M., Marchand, F., Hartley, R., Grist, J., Yip, P., McMahon, S.B., and Bradbury, E.J. (2006). Chondroitinase $\mathrm{ABC}$ promotes sprouting of intact and injured spinal systems after spinal cord injury. J. Neurosci. 26, 10856-10867.

Bradbury, E.J., Moon, L.D., Popat, R.J., King, V.R., Bennett, G.S., Patel, P.N. Fawcett, J.W., McMahon, S.B. (2002). Chondroitinase $\mathrm{ABC}$ promotes functional recovery after spinal cord injury. Nature 416, 636-640.

Caggiano, A.O., Zimber, M.P., Ganguly, A., Blight, A.R., and Gruskin, E.A. (2005). Chondroitinase ABCI improves locomotion and bladder function following contusion injury of the rat spinal cord. J. Neurotrauma 22, 226-239.

Carter, L.M., Starkey, M.L., Akrimi, S.F., Davies, M., McMahon, S.B., and Bradbury, E.J. (2008). The yellow fluorescent protein (YFP-H) mouse reveals neuroprotection as a novel mechanism underlying chondroitinase ABC-mediated repair after spinal cord injury. J. Neurosci. 28, 14107-14120.

Chau, C.H., Shum, D.K., Li, H., Pei, J., Lui, Y.Y., Wirthlin, L., Chan, Y.S., and Xu, X.M. (2004). Chondroitinase ABC enhances axonal regrowth through Schwann cell-seeded guidance channels after spinal cord injury. FASEB J. 18, 194-196.

Fouad, K., Pearse, D.D., Tetzlaff, W., and Vavrek, R. (2009). Transplantation and repair: combined cell implantation and chondroitinase delivery prevents deterioration of bladder function in rats with complete spinal cord injury. Spinal Cord $47,727-732$.

Fouad, K., Schnell, L., Bunge, M.B., Schwab, M.E., Liebscher, T., and Pearse, D.D. (2005). Combining Schwann cell bridges and olfactory-ensheathing glia grafts with chondroitinase promotes locomotor recovery after complete transection of the spinal cord. J. Neurosci. 25, 1169-1178.

García-Alías, G., Lin, R., Akrimi, S.F., Story, D., Bradbury, E.J., and Fawcett, J.W. (2007). Therapeutic time window for the application of chondroitinase $\mathrm{ABC}$ after spinal cord injury. Exp. Neurol. 210, 402-408.

Houle, J.D., Tom, V.J., Mayes, D., Wagoner, G., Phillips, N., and Silver, J. (2006). Combining an autologous peripheral ner- vous system "bridge" and matrix modification by chondroitinase allows robust, functional regeneration beyond a hemisection lesion of the adult rat spinal cord. J. Neurosci. 26, 7405-7415.

Huang, W.C., Kuo, W.C., Cherng, J.H., Hsu, S.H., Chen, P.R., Huang, S.H., Huang, M.C., Liu, J.C., and Cheng, H. (2006). Chondroitinase $\mathrm{ABC}$ promotes axonal re-growth and behavior recovery in spinal cord injury. Biochem. Biophys. Res. Commun. 349, 963-968.

Iaci, J.F., Vecchione, A.M., Zimber, M.P., and Caggiano, A.O. (2007). Chondroitin sulfate proteoglycans in spinal cord contusion injury and the effects of chondroitinase treatment. J. Neurotrauma 24, 1743-1759.

Ikegami, T., Nakamura, M., Yamane, J., Katoh, H., Okada, S., Iwanami, A., Watanabe, K., Ishii, K., Kato, F., Fujita, H., Takahashi, T., Okano, H.J., Toyama, Y., and Okano, H. (2005). Chondroitinase $\mathrm{ABC}$ combined with neural stem/progenitor cell transplantation enhances graft cell migration and outgrowth of growth-associated protein-43-positive fibers after rat spinal cord injury. Eur. J. Neurosci. 22, 3036-3046.

Iseda, T., Okuda, T., Kane-Goldsmith, N., Mathew, M., Ahmed, S., Chang, Y.W., Young, W., and Grumet, M. (2008). Single, high-dose intraspinal injection of chondroitinase reduces glycosaminoglycans in injured spinal cord and promotes corticospinal axonal regrowth after hemisection but not contusion. J. Neurotrauma 25, 334-349.

Kim, B.G., Dai, H.N., Lynskey, J.V., McAtee, M., and Bregman, B.S. (2006). Degradation of chondroitin sulfate proteoglycans potentiates transplant-mediated axonal remodeling and functional recovery after spinal cord injury in adult rats. J. Comp. Neurol. 497, 182-198.

Massey, J.M., Amps, J., Viapiano, M.S., Matthews, R.T., Wagoner, M.R., Whitaker, C.M., Alilain, W., Yonkof, A.L., Khalyfa, A., Cooper, N.G., Silver, J., and Onifer, S.M. (2008). Increased chondroitin sulfate proteoglycan expression in denervated brainstem targets following spinal cord injury creates a barrier to axonal regeneration overcome by chondroitinase $\mathrm{ABC}$ and neurotrophin-3. Exp. Neurol. 209, 426-445.

Massey, J.M., Hubscher, C.H., Wagoner, M.R., Decker, J.A., Amps, J., Silver, J., and Onifer, S.M. (2006). Chondroitinase $\mathrm{ABC}$ digestion of the perineuronal net promotes functional collateral sprouting in the cuneate nucleus after cervical spinal cord injury. J. Neurosci. 26, 4406-4414.

Shields, L.B., Zhang, Y.P., Burke, D.A., Gray, R., and Shields, C.B. (2008). Benefit of chondroitinase ABC on sensory axon regeneration in a laceration model of spinal cord injury in the rat. Surg. Neurol. 69, 568-577.

Tan, A.M., Colletti, M., Rorai, A.T., Skene, J.H., and Levine, J.M. (2006). Antibodies against the NG2 proteoglycan promote the regeneration of sensory axons within the dorsal columns of the spinal cord. J. Neurosci. 26, 4729-4739.

Tester, N.J., and Howland, D.R. (2008). Chondroitinase ABC improves basic and skilled locomotion in spinal cord injured cats. Exp. Neurol. 209, 483-496.

Tom, V., and Houlé, J.D. (2008). Intraspinal microinjection of chondroitinase $\mathrm{ABC}$ following injury promotes axonal regeneration out of a peripheral nerve graft bridge. Exp. Neurol. 211, 315-319.

Vavrek, R., Pearse, D.D., and Fouad, K. (2007). Neuronal populations capable of regeneration following a combined treatment in rats with spinal cord transection. J. Neurotrauma 24, 1667-1673.

Yick, L.W., So, K.F., Cheung, P.T., and Wu, W.T. (2004). Lithium chloride reinforces the regeneration-promoting effect of 
chondroitinase $\mathrm{ABC}$ on rubrospinal neurons after spinal cord injury. J. Neurotrauma 21, 932-943.

Yick, L.W., Cheung, P.T., So, K.F., and Wu, W. (2003). Axonal regeneration of Clarke's neurons beyond the spinal cord injury scar after treatment with chondroitinase ABC. Exp. Neurol. 182, 160-168.

Yick, L.W., Wu, W., So, K.F., Yip, H.K., Shum, D.K., (2000). Chondroitinase ABC promotes axonal regeneration of Clarke's neurons after spinal cord injury. Neuroreport. 11, 1063-1067.

Xia, Y., Zhao, T., Li, J., Li, L., Hu, R., Hu, S., Feng, H., and Lin, J. (2008). Antisense vimentin cDNA combined with chondroitinase $\mathrm{ABC}$ reduces glial scar and cystic cavity formation following spinal cord injury in rats. Biochem. Biophys. Res. Commun. 377, 562-566.

\section{Anti-Nogo approaches}

Atalay, B., Bavbek, M., Cekinmez, M., Ozen, O., Nacar, A., Karabay, G., and Gulsen, S. (2007). Antibodies neutralizing Nogo-A increase pan-cadherin expression and motor recovery following spinal cord injury in rats. Spinal Cord 45, 780-786.

Beaud, M.L., Schmidlin, E., Wannier, T., Freund, P., Bloch, J., Mir, A., Schwab, M.E., and Rouiller, E.M. (2008). Anti-Nogo-A antibody treatment does not prevent cell body shrinkage in the motor cortex in adult monkeys subjected to unilateral cervical cord lesion. BMC Neurosci. 9, doi:10.1186/1471-2202-9-5.

Bregman, B.S., Kunkel-Bagden, E., Schnell, L., Dai, H.N., Gao, D., and Schwab, M.E. (1995). Recovery from spinal cord injury mediated by antibodies to neurite growth inhibitors. Nature 378, 498-501.

Brosamle, C., Huber, A.B., Fiedler, M., Skerra, A., and Schwab, M.E. (2000). Regeneration of lesioned corticospinal tract fibers in the adult rat induced by a recombinant, humanized IN-1 antibody fragment. J. Neurosci. 20, 8061-8068.

Cao, Y., Shumsky, J.S., Sabol, M.A., Kushner, R.A., Strittmatter, S., Hamers, F.P., Lee, D.H., Rabacchi, S.A., and Murray, M. (2008). Nogo-66 receptor antagonist peptide (NEP1-40) administration promotes functional recovery and axonal growth after lateral funiculus injury in the adult rat. Neurorehabil. Neural Repair 22, 262-278.

Fouad, K., Klusman, I., and Schwab, M.E. (2004). Regenerating corticospinal fibers in the Marmoset (Callitrix jacchus) after spinal cord lesion and treatment with the anti-Nogo-A antibody IN-1. Eur. J. Neurosci. 20, 2479-2482.

Freund, P., Schmidlin, E., Wannier, T., Bloch, J., Mir, A., Schwab, M.E., and Rouiller, E.M. (2009). Anti-Nogo-A antibody treatment promotes recovery of manual dexterity after unilateral cervical lesion in adult primates-re-examination and extension of behavioral data. Eur. J. Neurosci. 29, 983-996.

Freund, P., Schmidlin, E., Wannier, T., Bloch, J., Mir, A., Schwab, M.E., and Rouiller, E.M. (2006). Nogo-A-specific antibody treatment enhances sprouting and functional recovery after cervical lesion in adult primates. Nat. Med. 12, 790-792.

Freund, P., Wannier, T., Schmidlin, E., Bloch, J., Mir, A., Schwab, M.E., and Rouiller, E.M. (2007). Anti-Nogo-A antibody treatment enhances sprouting of corticospinal axons rostral to a unilateral cervical spinal cord lesion in adult macaque monkey. J. Comp. Neurol. 502, 644-659.

GrandPre, T., Li, S., and Strittmatter, S.M. (2002). Nogo-66 receptor antagonist peptide promotes axonal regeneration. Nature 417, 547-551.

Lee, J.K., Chan, A.F., Luu, S.M., Zhu, Y., Ho, C., Tessier-Lavigne, M., and Zheng, B. (2009). Reassessment of corticospinal tract regeneration in Nogo-deficient mice. J. Neurosci. 29, 8649-8654.
Li, S., Liu, B.P., Budel, S., Li, M., Ji, B., Walus, L., Li, W., Jirik, A., Rabacchi, S., Choi, E., Worley, D., Sah, D.W., Pepinsky, B., Lee, D., Relton, J., and Strittmatter, S.M. (2004). Blockade of Nogo-66, myelin-associated glycoprotein, and oligodendrocyte myelin glycoprotein by soluble Nogo-66 receptor promotes axonal sprouting and recovery after spinal injury. J. Neurosci. 24, 10511-10520.

Li, S., and Strittmatter, S.M. (2003). Delayed systematic Nogo-66 receptor antagonist promotes recovery from spinal cord injury. J. Neurosci. 23, 4219-4227.

Liebscher, T., Schnell, L., Schnell, D., Scholl, J., Schneider, R., Gullo, M., Fouad, K., Mir, A., Rausch, M., Kindler, D., Hamers, F.P., and Schwab, M.E. (2005). Nogo-A antibody improves regeneration and locomotion of spinal cord-injured rats. Ann. Neurol. 58, 706-719.

Maier, I.C., Ichiyama, R.M., Courtine, G., Schnell, L., Lavrov, I., Edgerton, V.R., and Schwab, M.E. (2009). Differential effects of anti-Nogo-A antibody treatment and treadmill training in rats with incomplete spinal cord injury. Brain 132, 1426-1440.

Merkler, D., Metz, G.A., Rainteau, O., Dietz, V., Schwab, M.E., and Fouad, K. (2001). Locomotor recovery in spinal cord-injured rats treated with an antibody neutralizing the myelin-associated neurite growth inhibitor Nogo-A. J. Neurosci. 21, 3665-3673.

Raineteau, O., Fouad, K., Bereyre, F.M., and Schwab, M.E. (2002). Reorganization of descending motor tracts in the rat spinal cord. Eur. J. Neurosci. 16, 1761-1771.

Raineteau, O., Fouad, K., Noth, P., Thallmair, M., and Schwab, M.E. (2001). Functional switch between motor tracts in the presence of the mAb IN-1 in the adult rat. Proc. Natl. Acad. Sci. 98, 6929-6934.

Raineteau, O., Z'Graggen, W.J., Thallmair, M., and Schwab, M.E. (1999). Sprouting and regeneration after pyramidotomy and blockade of the myelin-associated neurite growth inhibitors NI 35/250 in adult rats. Eur. J. Neurosci. 11, 1486-1490.

Schnell, L., and Schwab, M.E. (1990). Axonal regneration in the rat spinal cord produced by an antibody against myelinassociated neurite growth inhibitors. Nature 343, 269-272.

Steward, O., Sharp, K., Yee, K.M., and Hofstadter, M. (2008). A re-assessment of the effects of a Nogo-66 receptor on regenerative growth of axons and locomotor recovery after spinal cord injury in mice. Exp. Neurol. 209, 446-468.

Thallmair, M., Metz, G.A., Z'Graggen, W.J., Raineteau, O., Kartje, G.L., and Schwab, M.E. (1998). Neurite growth inhibitors restrict plasticity and functional recovery following corticospinal tract lesions. Nat. Neurosci. 1, 124-131.

Von Meyenburg, J., Brosamle, C., Metz, G.A., and Schwab, M.E. (1998). Regeneration and sprouting of chronically injured corticospinal tract fibers in adult rats promoted by NT-3 and the $\mathrm{mAb}$ IN-1, which neutralizes myelin-associated neurite growth inhibitors. Exp. Neurol. 154, 583-594.

Wang, X., Baughman, K.W., Basso, D.M., and Strittmatter, S.M. (2006). Delayed Nogo receptor therapy improves recovery from spinal cord contusion. Ann. Neurol. 60, 540-549.

Wannier-Morino, P., Schmidlin, E., Freund, P., Belhaj-Saif, A., Bloch, J., Mir, A., Schwab, M.E., Rouiller, E.M., and Wannier, T. (2008). Fate of rubrospinal neurons after unilateral section of the cervical spinal cord in adult macaque monkeys: effects of an antibody treatment neutralizing Nogo-A. Brain Res. 1217, 96-109.

Z'Graggen, W.J., Metz, G.A., Kartje, G.L., Thallmair, M., and Schwab, M.E. (1998). Functional recovery and enhanced corticofugal plasticity after unilateral pyramid tract lesion and blockade of myelin-associated neurite growth inhibitors in adult rats. J. Neurosci. 18, 4744-4757. 


\section{Rho antagonists}

Chan, C.C., Khodarahmi, K., Liu, J., Sutherland, D., Oschipok, L.W., Steeves, J.D., and Tetzlaff, W. (2005). Dose-dependent beneficial and detrimental effects of ROCK inhibitor Y27632 on axonal sprouting and functional recovery after rat spinal cord injury. Exp. Neurol. 196, 352-364.

Dergham, P., Ellezam, B., Essagian, C., Avedissian, H., Lubell, W.D., and McKerracher, L. (2002). Rho signaling pathway targeted to promote spinal cord repair. J. Neurosci. 22, 65706577.

Dubreuil, C.I., Winton, M.J., and McKerracher, L. (2003). Rho activation patterns after spinal cord injury and the role of activated Rho in apoptosis in the central nervous system. J. Cell. Biol. 162, 233-243.

Fournier, A.E., Takizawa, B.T., and Strittmatter, S.M. (2003). Rho kinase inhibition enhances axonal regeneration in the injured CNS. J. Neurosci. 23, 1416-1423.

Lord-Fontaine, S., Yang, F., Diep, Q., Dergham, P., Munzer, S., Tremblay, P., and McKerracher, L. (2008). Local inhibition of Rho signaling by cell-permeable recombinant protein BA-210 prevents secondary damage and promotes functional recovery following acute spinal cord injury. J. Neurotrauma 25, 13091322.

Nishio, Y., Koda, M., Kitajo, K., Seto, M., Hata, K., Taniguchi, J., Moriya, H., Fujitani, M., Kubo, T., and Yamashita, T. (2006). Delayed treatment with Rho-kinase inhibitor does not enhance axonal regeneration or functional recovery after spinal cord injury in rats. Exp. Neurol. 200, 392-397.
Sung, J.K., Miao, L., Calvert, J.W., Huang, L., Louis, H.H., and Zhang, J.H. (2003). A possible role of RhoA/Rho-kinase in experimental spinal cord injury in rat. Brain Res. 959, 29-38.

Tanaka, H., Yamashita, T., Yachi, K., Fujiwara, T., Yoshikawa, H., and Tohyama, M. (2004). Cytoplasmic p21(Cip1/WAF1) enhances axonal regeneration and functional recovery after spinal cord injury in rats. Neuroscience 127, 155-164.

Yamagishi, S., Fujitani, M., Hata, K., Kitajo, K., Mimura, F., Abe, H., and Yamashita, T. (2005). Wallerian degeneration involves Rho/Rho-kinase signaling. J. Biol. Chem. 280, 20384-20388.

\section{Discussion}

Fleming, J.C., Norenberg, M.D., Ramsay, D.A., Dekaban, G.A., Marcillo, A.E., Saenz, A.D., Pasquale-Styles, M., Dietrich, W.D., and Weaver, L.C. (2006). The cellular inflammatory response in human spinal cords after injury. Brain 129, 32493269 .

Address correspondence to: Brian K. Kwon, M.D., Ph.D., FRCSC Blusson Spinal Cord Center, Room 6196 818 West 10th Avenue Vancouver, British Columbia Canada V5Z 1 M9

E-mail: brian.kwon@vch.ca 